\title{
Convective Rainfall in Amazonia and Adjacent Tropics
}

\author{
Augusto J. Pereira Filho1, Richard E. Carbone'2, John D. Tuttle'2, Hugo A. Karam³ \\ ${ }^{1}$ Department of Atmospheric Sciences, Institute of Astronomy, Geophysics and Atmospheric Sciences, \\ University of São Paulo, São Paulo, Brazil \\ ${ }^{2}$ National Center for Atmospheric Research, Colorado, USA \\ ${ }^{3}$ Department of Meteorology, Federal University of Rio de Janeiro, Rio de Janeiro, Brazil \\ Email: augusto.pereira@iag.usp.br, carbone@ucar.edu, tuttle@ucar.edu, hugo@igeo.ufrj.br
}

Received 5 February 2015; accepted 23 April 2015; published 30 April 2015

Copyright (C) 2015 by authors and Scientific Research Publishing Inc.

This work is licensed under the Creative Commons Attribution International License (CC BY). http://creativecommons.org/licenses/by/4.0/

(c) (i) Open Access

\section{Abstract}

Hourly rainfall estimates from integrated satellite data are used to build a dynamically based climatology of convectively generated rainfall across South America, including tropical, sub-tropical and oceanic regions. Herein, we focus on $0 \mathrm{~S}$ to 15S, including greater Amazon and NE Brazil leeward of the South Atlantic Ocean. Emphasis is placed on rainfall resulting from organized convective regimes, which are known to produce the majority of seasonal rainfall in various parts of South America and other continents. The statistical characteristics of individual events are quantified and examined with respect to regional atmospheric conditions. Among the factors considered are steering winds and wind shear, convective available potential energy (CAPE), sea and land breezes, and the occurrence of transient disturbances such as Kelvin Waves and Easterly Waves. Forcing and convective triggering mechanisms are inferred from the diagnosis of systematic patterns as evidenced in the continental diurnal cycle and longer periods of natural variability. The episodes of organized convection are analyzed in terms of their duration, span, phase speed, starting and ending time, starting and ending longitude, month and year through frequency distribution analysis. Most episodes of organized convection tend to move westward across the Amazon Basin. Descriptive statistics indicate average phase speed of westward and eastward episodes of convection in the Amazon basin at $-11.8 \mathrm{~m} \cdot \mathrm{s}^{-1}$ and $13.0 \mathrm{~m} \cdot \mathrm{s}^{-1}$, respectively. Eastward propagating systems are influenced by northeastward moving cold fronts in Southern South America and tend to trigger and to organize convection across the Amazon Basin. Hourly rainfall analyses indicate that convection over the Amazon region is often organized.

\section{Keywords}

Satellite-Derived Rainfall, Organized Convection, La Plata Basin, Amazon Basin, Diurnal Cycle 


\section{Introduction}

New high spatial and temporal resolution precipitation accumulation estimates such as the ones obtained from integrating passive microwave (PMW) and IR imagers sensors onboard geostationary and polar orbit satellites are providing renewed and inedited opportunities to better comprehend this important component of the global hydrological cycle. Recently, a new rainfall estimation technique based on the afore mentioned PMW and thermal IR datasets termed the Climate Prediction Center morphing method or CMORPH was developed by [1]. These unprecedented rainfall accumulation estimates at half-hour time intervals with $8-\mathrm{km} \times 8$-km spatial resolution open up new opportunities for more in-depth studies of precipitating systems and associated dynamics and thermodynamics, spatial and temporal evolution. The aim of this work is to use CMOPRH hourly rainfall estimates over South America (Figure 1) to study the diurnal cycle of convection and underlying dynamics and thermodynamics of mesoscale in the Amazon.

The diurnal cycle of precipitation over the Amazon basin has been studied with rainfall estimation obtained from IR-based methods [2] [3], with cold cloud top frequency also infer from IR imagers [4], limited number of rain gage with fairly long records [5], with weather radars used in experiments [6], among other means. Some of these studies were based on long time series over large areas, but with fairly low temporal sampling rates, others were based on shorter time series over limited areas but with multiple sensors and high sampling rate measurements [7]. Though limited by these constraints, these previous studies have contributed in understating precipitation regimes.

The diurnal cycle of rainfall is especially informative with respect to the frequency and phase of rainfall associated with long-lived propagating rainfall "episodes". Similar to findings in tropical northern Africa and tropical northern Australia, in the Brazilian Amazonian forest there is a strong presence of organized convection, which can propagate zonally hundreds to thousands of kilometers as a coherence sequence of mesoscale convective systems. Convective triggering is often associated with elevated, or otherwise complex, terrain, including sea breezes, the Andes, and basin regions, which are especially rich in moist static energy. The passage of Kelvin Waves appears to be the most likely explanation of eastward-propagating clusters of convection, within which westward-propagating systems often reside.
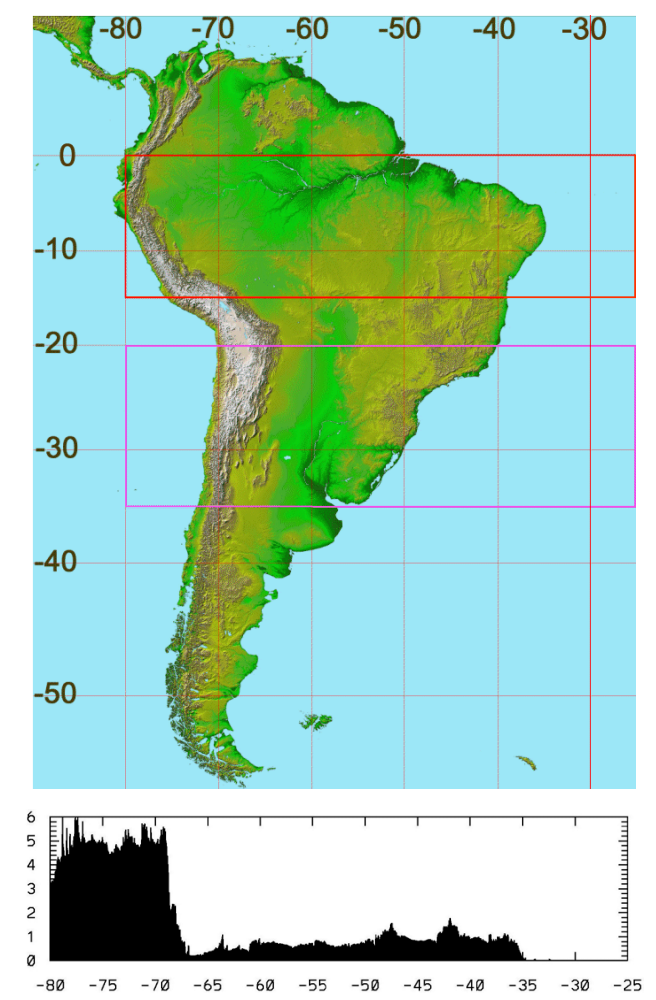

Figure 1. Topographic map of South America latitudes, longitudes and boxes over the Amazon Basin (red) and La Plata Basin (purple) are indicated. Source: NASA/JPL/NIMA. 
This work proposes the analysis of the organized convection over the Amazon by means of hourly rainfall estimates, obtained with the CMOPRH method described by [1]. To our knowledge from literature, the applied rainfall estimates, at 8-km spatial resolution, from December 2002 to June 2008, with very few missing data, is one of the most complete, longest and highest resolution data sets available to date that allows a comprehensive description of spatial and temporal distribution of convection from its hourly to inter-annual variability over the entire continent. In this work, diurnal, intra and inter seasonal and inter-annual cycles are obtained and examined in the light of episodes of organized convection.

Daily, monthly and yearly spatial patterns of rainfall accumulation over South America vary inter and intra seasonally forced by the respective underlying dynamic and thermodynamics. Time-longitude diagrams of MORPH hourly rainfall are used to describe the genesis, structure, longevity, phase speed and inferences of the underlying dynamics and thermodynamics of episodes of organized convection. The episodes of organized convection are analyzed in terms of their duration, span, phase speed, starting and ending time, starting and ending longitude, month and year through frequency distribution analysis.

As assigned above, the rainfall distribution dataset used correspond to a period of 6.5 years long, with few missing data over the full area of South America. CMORPH was used to study the diurnal cycle of convection regionally and globally [8], to analyze the frequency of precipitation as a function of the time of the day during the austral summers of 2003 and 2004 [9] and kinematics aspects of propagating convective systems. In the present work, the diurnal cycle of convection over the Amazon is analyzed through time-longitude diagrams or Hovmöller diagrams. Details of the analysis are provided in the next section.

The dataset used in this study is 6.5 years long with few missing data over South America. CMORPH was used to study the diurnal cycle of convection regionally and globally [8], to analyze the frequency of precipitation as a function of the time of the day during the austral summers of 2003 and 2004 [9] and kinematics aspects of propagating convective systems. In the present work, the diurnal cycle of convection over the Amazon is analyzed through time-longitude diagrams or Hovmöller diagrams. Details of the analysis are provided in the next section.

\section{Methodology}

\subsection{CMORPH Description}

CMORPH ("CPC Morphing technique"; [1] provides high spatial ( $\sim 8 \mathrm{~km}$ at the equator) and temporal (halfhourly) analyses of precipitation globally from $60^{\circ} \mathrm{N}$ to $60^{\circ} \mathrm{S}$. The method [1] blends together precipitation estimates from passive microwave (PMW) instruments (SSMI, AMSR-E, AMSU, TMI) that are generated from published algorithms. However, since these instruments are housed on low earth orbit platforms, sampling frequency is a major shortcoming. CMORPH alleviates this sampling problem by using geosynchronous infrared (IR) data as a mechanism to interpolate and "morph" the PMW-derived precipitation estimates yielding spatially and temporally complete precipitation fields every $1 / 2$ hour. CMORPH differs from other combined IR/PMW methods (e.g., TMPA; [10]; PERSIANN; [11]) it utilizes IR to estimate the motion of raining systems, and applies that motion field to raining systems that have been determined from passive microwave (PMW) information. Further details can be found in [1]. Figure 1 shows a topographic map of South America and the area where daily, monthly and yearly rainfall accumulation were estimated with CMOPRH rainfall estimates to depict the interannual, intraseasonal and daily cycle of convection over the Amazon from 2003 to 2007 . The study area is within the rectangle determined by latitudes $0^{\circ} \mathrm{S}$ to $-40^{\circ} \mathrm{S}$ and by longitudes $-25^{\circ} \mathrm{W}$ to $-80^{\circ} \mathrm{W}$.

\subsection{Hovmöller Diagrams}

Time-distance plots (Hovmöller diagrams) have been used by [12] to study the coherency, longevity and zonal distance (span). This study uses the same method for CMORPH rainfall estimates at one-hour accumulation with approximately $8-\mathrm{km}$ spatial resolution within the two rectangles shown in Figure 1 over the Amazon Basin and the La Plata Basin [13]. Two-dimensional autocorrelation functions are fitted to the rainfall data in Hovmöller space (e.g., Figure 10(a)). The function is rectangular in one direction and cosine-weighted in the other perpendicular direction. The function is stepped through all time-longitude positions at 1 -hour per $0.2^{\circ}$. Sequences of contiguous fits define the coherent span, duration and propagation characteristics for each rain streak. A rainfall and correlation minimum thresholds are required to the fit to become part of the statistics. Further de- 
tails are found in [12] as well as in [13] [14]. The phase speed and spatial coherence of rainfall events can lend insight to the underlying dynamics of precipitation systems. Features tilted toward the east (west) indicate propagation in that direction. Features that are fixed in one given longitude are stationary. The tilt of the features in the diagram is proportional to their phase speed. The Hovmöller diagrams were plotted at 15-day time intervals.

\section{CMORPH Rainfall Climatology}

Figure 2 shows the annual one-hour rainfall average over South America for 2007. There are seven major rainfall patterns common to all years: 1) An area of high rainfall accumulations over the Amazon Basin; 2) A secondary area of high rainfall accumulation over the La Plata basin; 3) A broad area of fairly high precipitation over South Atlantic Ocean; 4) A very low rainfall area associated to the South Atlantic high pressure system; 5) An area of low rainfall associated with South Pacific high pressure system; 6) An artificial low rainfall stripe along the coast of Brazil due to warn rain processes; 7) Four high rainfall centers downwind from the Andes Mountains in the Amazon Basin. These rainfall patterns have greater interannual variability in amplitude than phase modulated by stationary and transient climate features [15] [16] have compared gauge-measured and CMOPRH-derived rainfall accumulation over the same region for 2003 and 2004. Both measured and estimated rainfall tend to be better correlated for longer accumulation time intervals with $\rho^{2}=0.7,0.6$ and 0.4 for yearly, monthly and daily rainfall accumulation. The rainfall amplitude has a significant impact on the water budget over two major watersheds of South America, namely, the Amazon and the La Plata Basins. Recently, the Amazon Basin had a record drought (2005) followed by record flood (2009) that affected most cities in the Amazon with a shortage of fresh water and transportation difficulties. On the other hand, the La Plata basin experienced the opposite at the same time with floods in 2005 and droughts in 2009 . These two major hydrological events were associated with a weak El Niño and weak La Niña conditions, respectively. This new high-resolution satellite rainfall estimates are an important source of information for water resources and water management to anticipate such extreme hydro-climatic conditions [16].

December, January and February are the summer months in the AS, and also correspond to the period of time between two sequential years. So, the annual total showed in Figure 2, contains half of the summer months of two consecutive years. Therefore, the accumulated fields showed in Figure 2 better corresponds to chronological years than the hydrometeorological years, being that the later starts in the minimum of the regional precipitation, which in SA occurs in July, not January. This explains the apparently small inter-annual variability computed, even so considering the year of 2005 (not shown), that was extremely dry in some part of the Amazon basin. This is an issue to be fully explored in a future research. For now, it can be said that a displacement of the beginning of the hydrometeorological year may imply a better resolution of the inter-annual variability of the

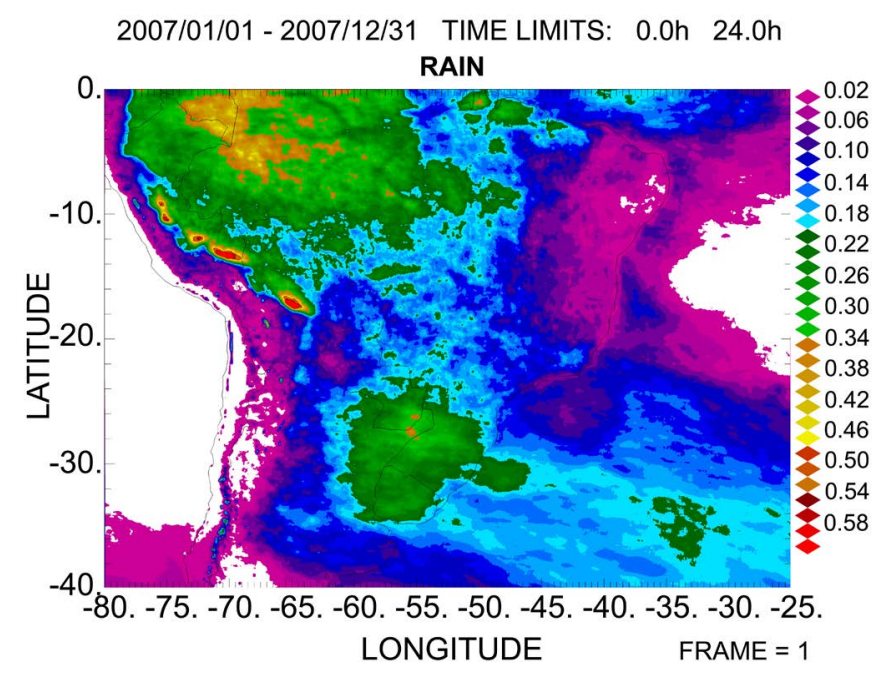

Figure 2. Yearly one-hour rainfall rate average over South America for 2007. Longitudes, latitudes, geographic contours, color scale $\left(\mathrm{mm} \cdot \mathrm{hr}^{-1} \cdot \mathrm{year}^{-1}\right)$ are indicated. Adapted from [22]. 
rainfall field in SA. For mid-latitude countries, it is usual the hydrometeorological year begins in January, because the larger amount of the precipitation occurs during the winter. Differently, in the tropical belt the hydrometeorological year starts conventionally in winter, during the dry period (i.e., six months before the corresponding start in mid-latitudes). That is, of course, a hydrometeorological point of view, which may be useful for accounting the fresh water and the enthalpy available in a forest environment to biomass support.

Figure 3 shows the time evolution of the diurnal cycle of precipitation for 2003. The time evolution of the

0000-0300 UTC

2003/01/31 - 2003/12/31 TIME LIMITS: $-0.5 \quad 3.5$

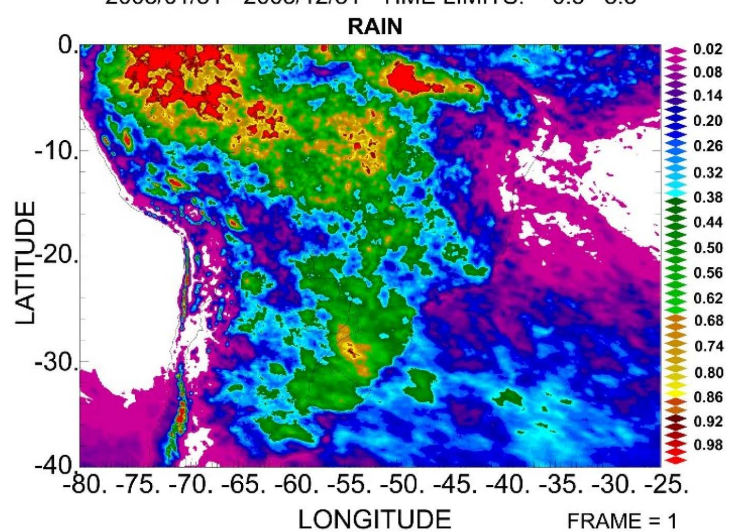

0600-0900 UTC

2003/01/31 - 2003/12/31 TIME LIMITS: 6.59 .5

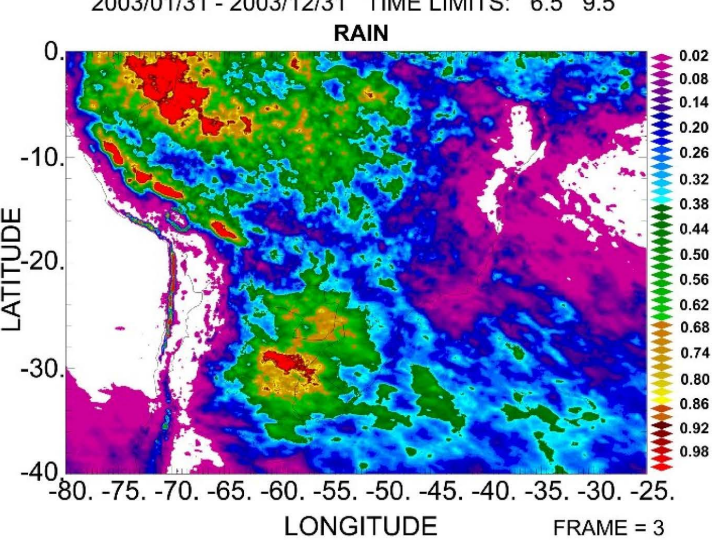

1200-1500 UTC

2003/01/31 - 2003/12/31 TIME LIMITS: 12.515 .5

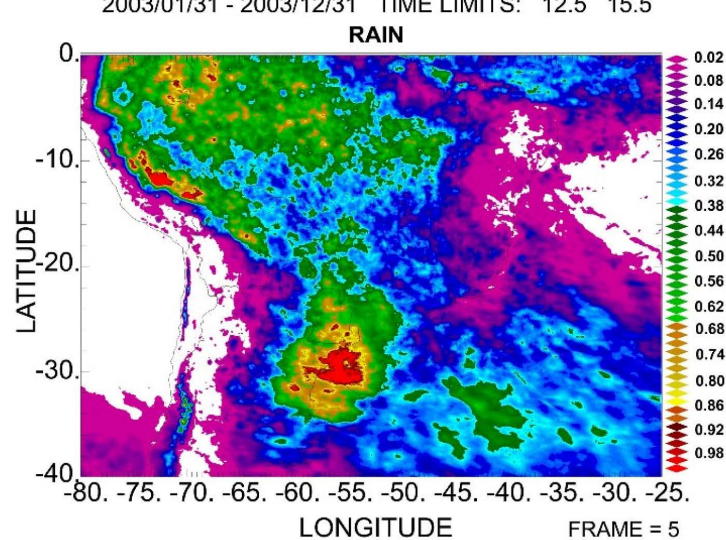

1500-1800 UTC

2003/01/31 - 2003/12/31 TIME LIMITS: 15.518 .5

RAIN

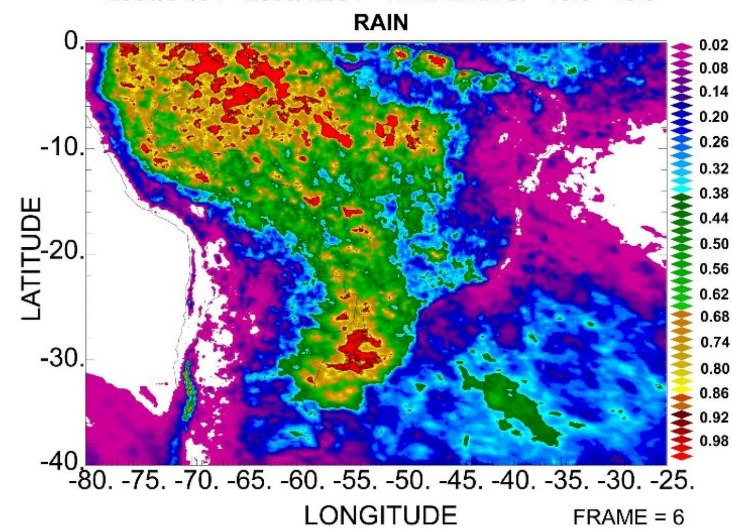

1800-2100 UTC

2003/01/31 - 2003/12/31 TIME LIMITS: 18.521 .5

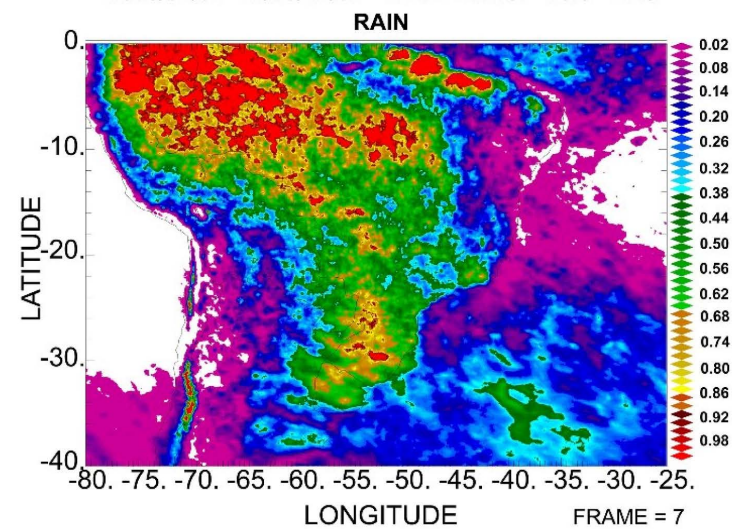

2100-0000 UTC

2003/01/31 - 2003/12/31 TIME LIMITS: 21.524 .5

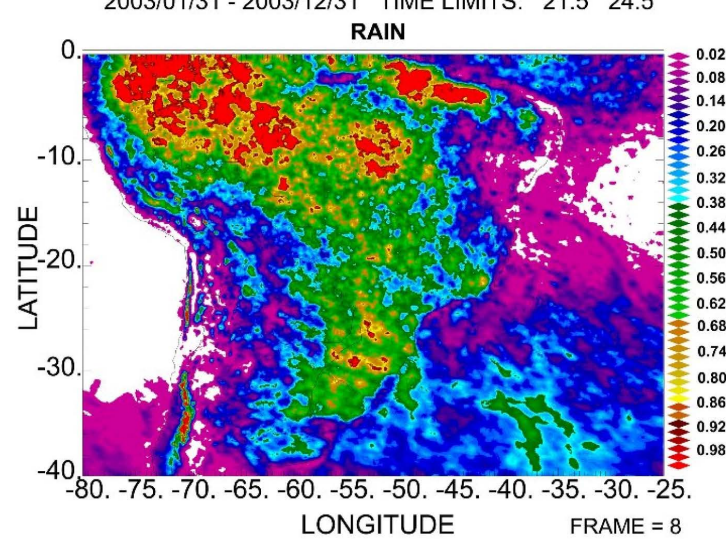

Figure 3. Yearly three-hour rainfall rate scale $\left(\mathrm{mm} \cdot \mathrm{hr}^{-1} \cdot \mathrm{year}^{-1}\right)$ over South America for 2003. Longitudes, latitudes, geographic contours, color scale $\left(\mathrm{mm} \cdot \mathrm{hr}^{-1} \cdot \mathrm{year}^{-1}\right)$ are indicated. Adapted from [22]. 
one-hour rainfall accumulation average at 3-hour time interval are shown for the indicated times. The diurnal cycle of convection over western Amazon Basin is quite remarkable. There is a minimum in mid morning and a maximum in the mid afternoon. Over the Brazilian northern coast the maximum has a three-hour delay. Over the Chaco region the diurnal cycle is well defined. The local maximum over Peru and Bolivia close to the Andes Mountains occur in the morning hours, likely from the differential diabatic heating associated with elevated terrain in the west.

Apparently high precipitation accumulation over the Andes at $-40^{\circ} \mathrm{S}$ to $-20^{\circ} \mathrm{S}$ over the entire day is probably an artifact, resulting from ice and snow on top of the mountains. As CMOPRH uses PMW with lower resolution, the surface correction seems inappropriate in this case. These results agree with previous studies (e.g., [3] [5] [9] [17]). The interannual diurnal cycle indicates that 2004 was wetter given the larger amplitude of precipitation especially between 1500 UTC and 2100 UTC while 2005 was the driest because of the significant reduction of rainfall between 0000 UTC and 1500 UTC (not shown). It can be suggested that the greater rainfall accumulation in the afternoon hours of 2004 might have reduced the water vapor supply to the MCS in the La Plata Basin. Also, the impact of the South Atlantic high-pressure system was somehow greater in 2005 (not shown).

The frequency of hourly rainfall in the Amazon basin is shown in Figure 4 for December, January e February of 2003 to 2007 . A remarkable seasonal variance on the diurnal cycle is caused by the ITCZ displacement that reaches $10^{\circ} \mathrm{S}$ in summer and $15^{\circ} \mathrm{N}$ in winter (not shown).

It is worth to stress the role of the precipitation in the definition of the South Atlantic Convergence Zone, or SACZ, during DJF and SON (not Shown) months late afternoon and night. The maximum convective activity occurs in late afternoon hours in all seasons with more (less) wide spread and intense precipitation over most of the Amazon basin and southward (northward) in summer (winter).

The diurnal cycle in summer has two maximal frequencies of rainfall between 0200 UTC and 0800 UTC (secondary) and between 1400 UTC and 0000 UTC (primary) with minimal between 0900 UTC and 1300 UTC and 0000 UTC and 0100 UTC. Both regions of higher frequency of rainfall are oriented NW-SE. Thus, diurnal and intra-seasonal (not shown) spatial-temporal variations are quite remarkable and controlled by the diurnal, seasonal and annual diabatic heating cycles and underlying equatorial wave dynamics as will be indicated through relevant instances of organized convection.

\section{Characteristics of Organized Convection}

Most organized convection moves westward all year round and some episodes can last longer than 3 days going cross the Amazon basin. Convection tends to be more organized and last longer between March and June while more stationary or short lived between October and February. Convection is short lived and limited to northwest Amazon basin between July and September. Concomitantly the spread of giant convective cells to west over the Amazon, there is also a spread of convective clusters toward the east, thus defining a board type pattern on the Hovmöller diagram.

Figure 5 shows an episode of wide spread deep convection across the Amazon Basin between 11 and 18 March 2003. Figure 5(a) shows the Hovmöller diagram of hourly average rainfall accumulation. A complex pattern of time-longitude rainfall structures include the diurnal cycle of convection that starts in the early afternoon hours. For instance, the convection initiates at about 1500 UTC 11 March 2013 between $-35^{\circ} \mathrm{W}$ and $-55^{\circ} \mathrm{W}$ forming a straight timeline. It can be clearly seen at the same starting two days later.

It was seen in Figure 5(a) other slanted structures that start in one given time and longitude and move westward with time such as the one that stated on 1500 UTC 11 March at $-70^{\circ} \mathrm{W}$ and ended on 0200 UTC 13 March 2003 at $-75^{\circ} \mathrm{W}$. Roughly, it moved more than $500 \mathrm{~km}$.

Similar slanted features are present through the time longitude domain. In other instances, the slanted rainfall systems is intermittent and with variable phase speeds and spans. A time-longitude region of weak or stationary rainfall is observed between 0000 UTC 12 March and 1200 UTC 14 March 2003 between $-25^{\circ} \mathrm{W}$ to $-40^{\circ} \mathrm{W}$. A more interesting feature is the apparent organization of eastward wave train transversal to the westward moving systems that starts on 1200 UTC 11 March at $-75^{\circ} \mathrm{W}$ and ends on 0000 UTC 17 March 2013.

It might be a Kelvin wave moving through the domain and interacting with the diurnal cycle and the organized convection. Figure 5(b) shows respective Hovmöller diagram of the average 700-hPa zonal winds. It shows a convergence zone of more intense easterlies and weaker westerlies. The former results in oceanic moist advection. Noteworthy is the reduction in the easterlies coinciding with the time-longitude region of weak preci- 

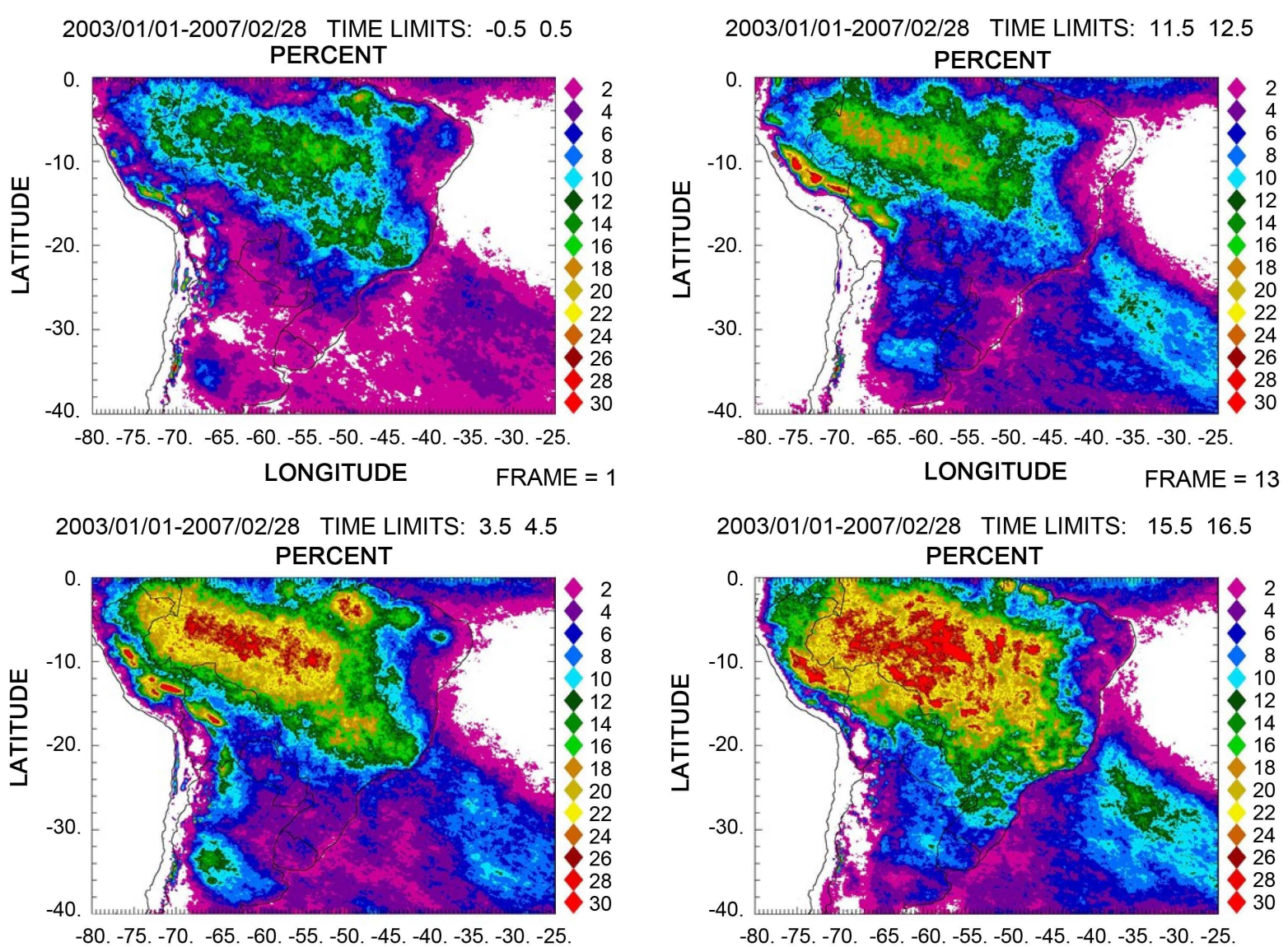

LONGITUDE $\quad$ FRAME $=5$
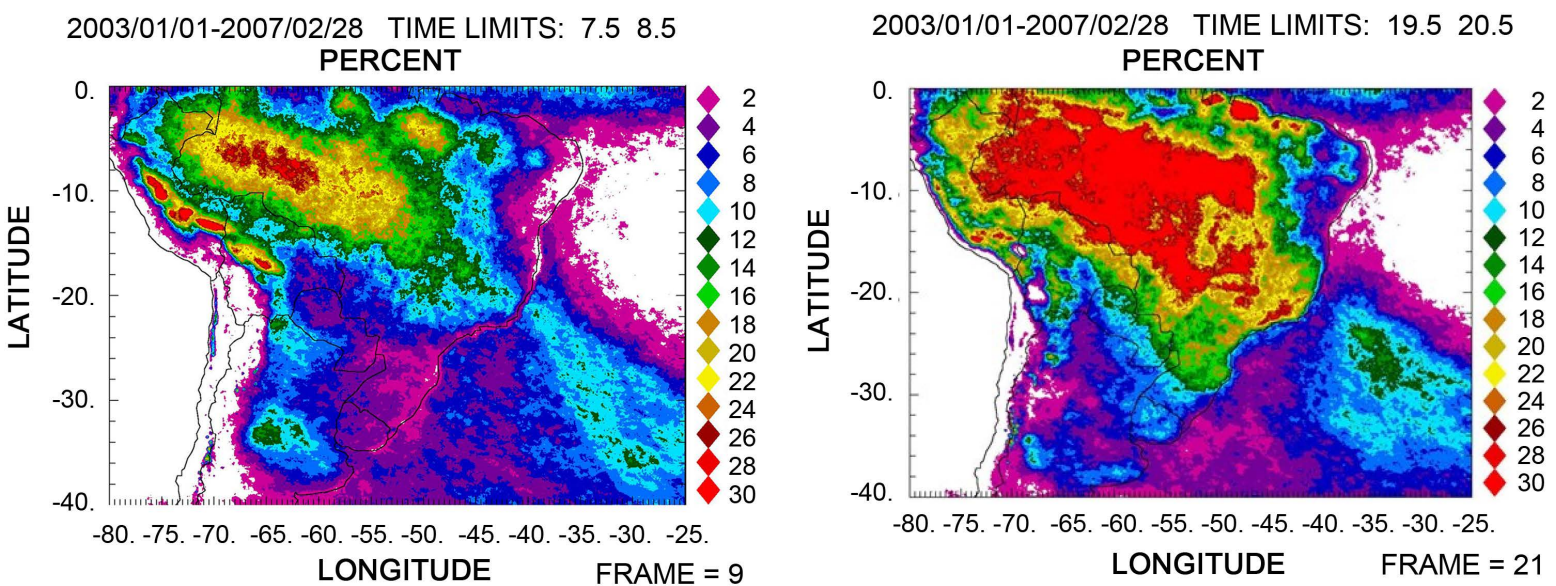

Figure 4. Frequency of hourly rainfall at 0000 UTC, 0400 UTC, 0800 UTC, 1200 UTC, 1600 UTC and 2000 UTC for summer months (DJF) over South America between 2003 and 2007. Longitudes, latitudes, geographic contours, color scale (\%) are indicated. Adapted from [22].

pitation indicated in Figure 5(a). The convergence zone moves eastward with similar phase speed of the transversal wave train probably associated to a Kelvin wave. The time-longitude diagram of 500-hPa meridional winds is in Figure 5(c). It shows a wave train of equally intense southerly and northerly winds propagating eastward or a high-pressure system associated with the convection. Figure 5(d) is the composite of 850-hPa winds between 11 and 18 March 2003 where a intense low level easterly jet was between the Equator and $-5^{\circ} \mathrm{S}$, 


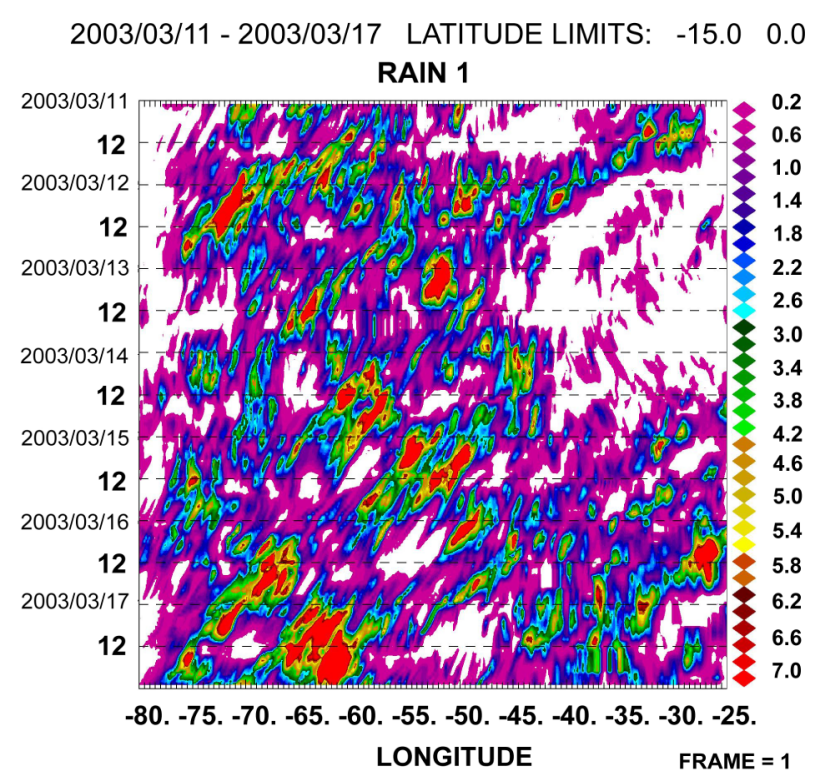

(a)

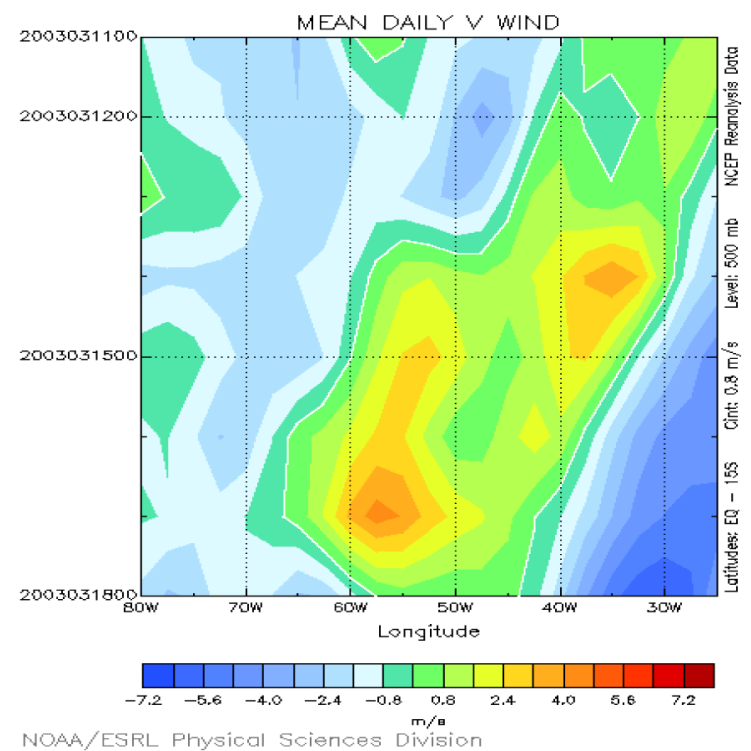

(a)

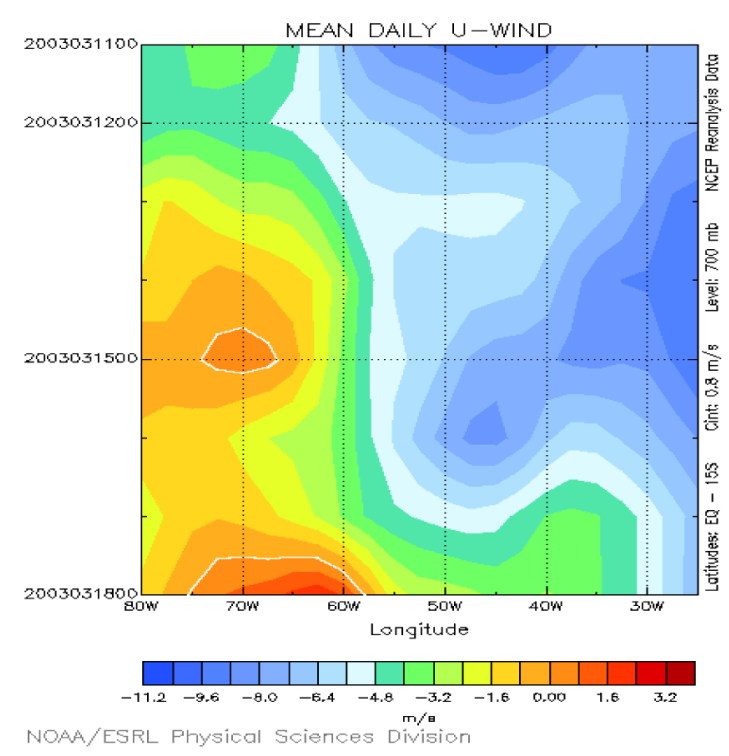

(b)

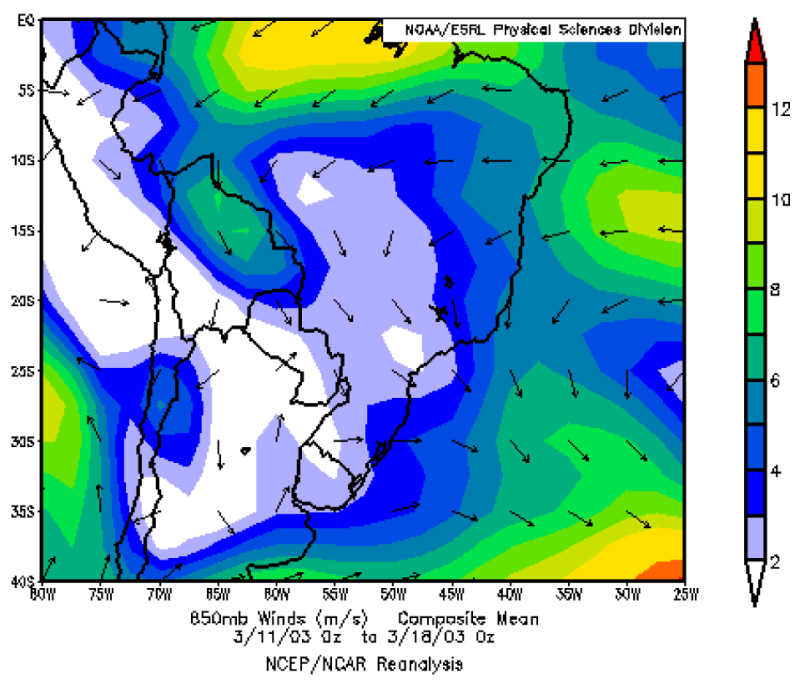

(b)

Figure 5. Episodes of organized convection between 11 and 18 March 2003. It shows Hovmöller diagrams of one-hour rainfall accumulation $\left(\mathrm{mm}^{-1} \mathrm{hr}^{-1}\right.$ ) (a), 700-hPa zonal wind (b) and 500-hPa meridional wind fields (c), and the average $850-\mathrm{hPa}$ wind field (d). Longitudes, latitudes, geographic contours, and color scales are indicated.

and $-40^{\circ} \mathrm{W}$ and $-70^{\circ} \mathrm{W}$ and, another further east less intense over the Atlantic Ocean between $-10^{\circ} \mathrm{S}$ and $-15^{\circ} \mathrm{S}$.

The South American low-level jet is also apparent in Figure 5(d). Thus, this instance of intense convective activity over the Amazon basin is a very complex one with diabatic heating, mesoscale and large scale forcing mechanisms. The seemingly chaotic rainfall structure of the Amazon has some degree of organization by such dynamic and thermodynamic forcing. All individual episodes in this and the following examples and within the whole CMORPH dataset were computed by means of Hovmöller diagram analysis to estimate phase speeds, spans and durations that will be shown in Section 6.

The rainfall episodes of organized convection shown in Figure 6 are an example of Kevin waves mixed with westward propagating systems and also the regular diurnal cycle. The longest system goes across the time-longitude domain in 5 days from $-75^{\circ} \mathrm{W}$ to $-40^{\circ} \mathrm{W}$ (Figure 6(a)). Individual systems tend to propagate westward 


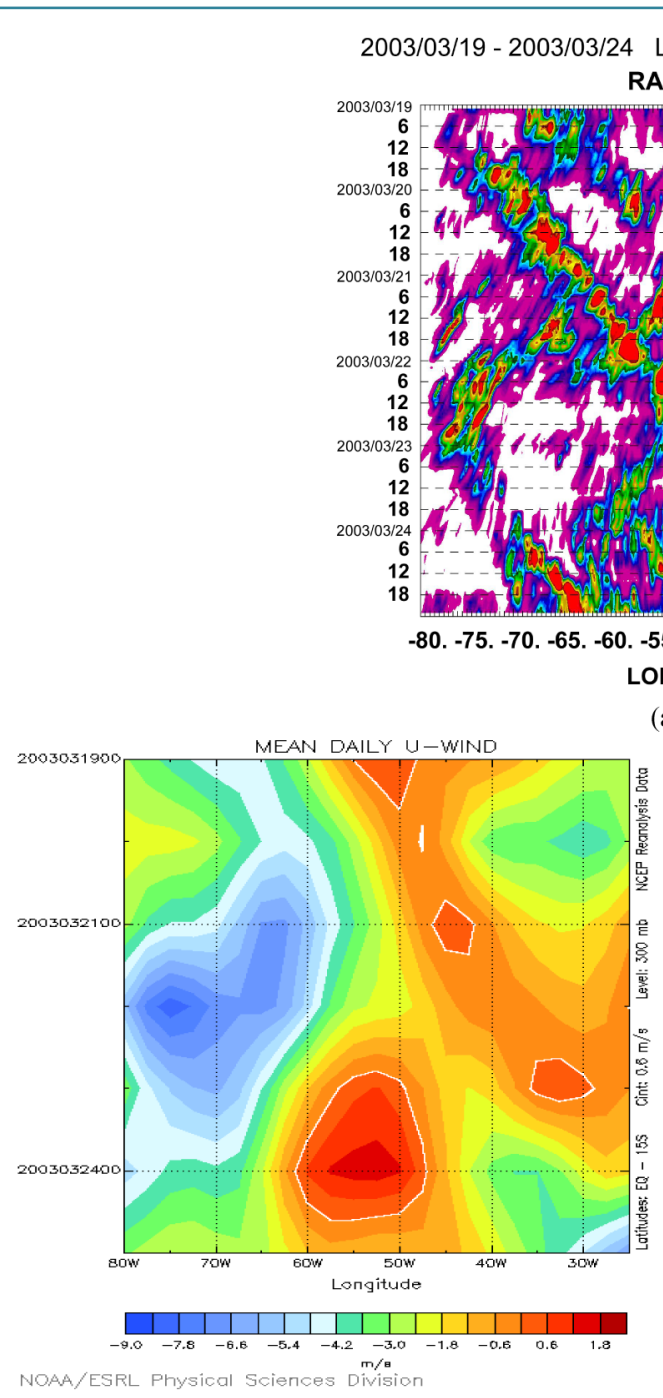

(b)

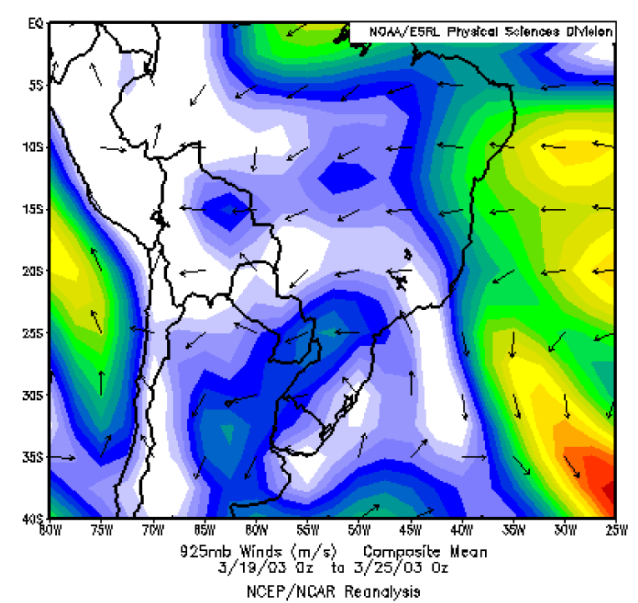

(d)

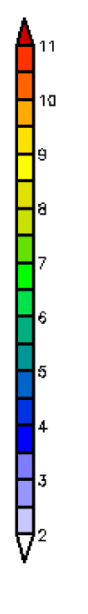

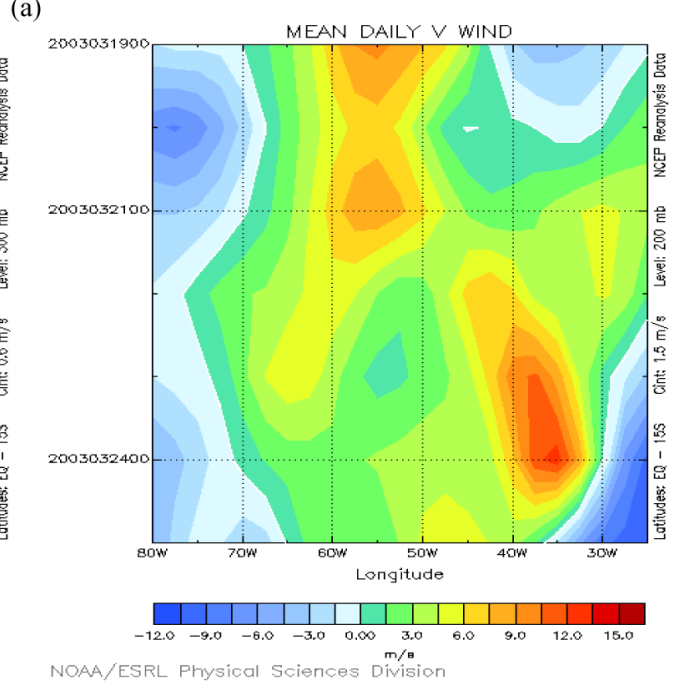

(c)

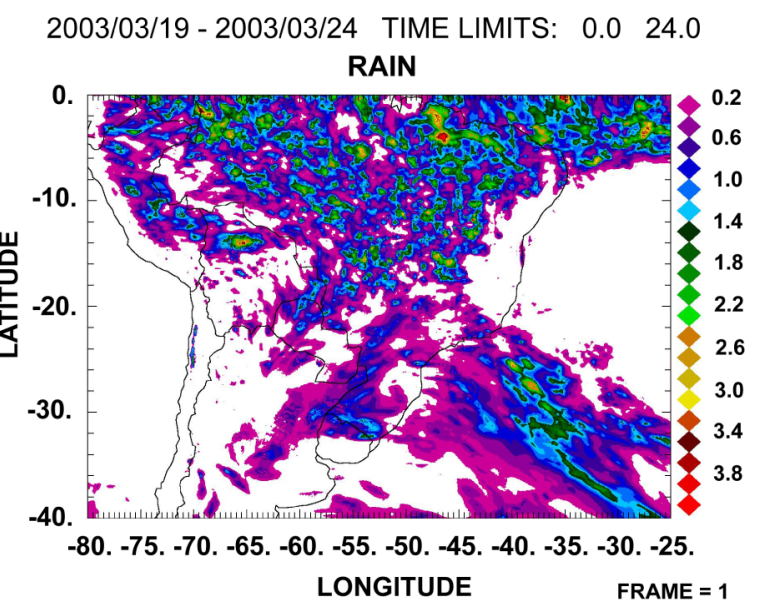

(e)

Figure 6. Episodes of organized convection between 19 and 24 March 2003. It shows Hovmöller diagrams of one-hour rainfall accumulation $\left(\mathrm{mm} \cdot \mathrm{hr}^{-1}\right)$ (a), 300-hPa zonal wind (b) and 200-hPa meridional wind fields (c), and averages of 925 $\mathrm{hPa}$-wind (d) field and of hourly precipitation (e). Longitudes, latitudes, geographic contours, and color scales are indicated. 
within this long wave train at even slower phase speed or stationary as the ones that start on 1800 UTC 21 March 2003 at $-47^{\circ} \mathrm{W}$ and $-50^{\circ} \mathrm{W}$ that last almost two days with apparent intensification as the moving through the wave envelop. The more stationary and intense rainfall system is observed downstream near the Atlantic Ocean on 1800 UTC 22 March 2003 between $-45^{\circ} \mathrm{W}$ and $-48^{\circ} \mathrm{W}$. There are instances of Kevin wave trains in Figure 6(a) with similar phase speeds that enter the time-longitude domain at $-50^{\circ} \mathrm{W}$ and $-38^{\circ} \mathrm{W}$.

Following [18] [19], the Kelvin equatorial waves are able to carry out information rapidly eastward, by creating easterly trade winds associated with a Walker type cells (i.e., circulations with rising motion over the heat source regions and a sinking motion to their east). The regular diurnal cycle is less apparent in this case since the Kevin wave train tends to dry the environment around it as can be seen in Figure 6(a) to the left and to the right of the weather systems within the region influence by the Kevin wave. The Hovmöller 300-hPa zonal wind in Figure 6(b) indicates that westerlies winds were dominant in the time-longitude domain with winds up to -9.0 $\mathrm{m} \cdot \mathrm{s}^{-1}$ observed on 0000 UTC 22 March 2003 at $-75^{\circ} \mathrm{W}$. Zonal divergence and convergence (Figure 6(b)) are over higher and lower rainfall accumulation regions (Figure 6(a)), respectively. 200-hPa meridional winds on the other hand were northward except close to Andes Cordillera and over the Ocean (Figure 6(c)). The wave train of relative low and high pressure associated to the meridional wind field is tilted westward. Also, stronger northward meridional winds are observed to the left of the moving Kevin wave. The 925-hPa wind field shown in Figure 6(d) shows a jet confined to $5^{\circ}$ latitude from the Equator where Kevin waves are observed. The average CMORPH 1-hour rainfall accumulation field over South America during the episode is shown in Figure 6(e). Two main regions of precipitation are across the Equator down to $-20^{\circ} \mathrm{S}$ and over the South Atlantic Ocean (SAO) resulting from the Kelvin waves and baroclinic waves in Amazonia and the SAO regions, respectively.

An intense long-lived westward moving wave is shown in Figure 7. It moves through and intensifies the regular diurnal cycle, clearly seen during the entire period in Figure 7(a). The 700-hPa zonal winds were weaker westward with zonal convergence at the time-longitude where the wave formed over northeast Brazil (Figure 7(b)). The 200-hPa meridional winds show a symmetric pattern of anti-cyclonic rotation in the longitude domain (Figure 7(c)) between 0000 UTC 04 November to 0000 UTC 0600 UTC that become cyclonic afterwards. The westward propagating system move associated to the region associated with northward meridional winds. Figure 7(d) shows the $850 \mathrm{hPa}$ wind field that were more intense over Northeast Brazil, so stronger convergence was where the convection associated with the easterly wave formed. The average CMORPH 1-hour accumulation field shown in Figure 8(e) indicates greater rainfall accumulations over Northeast Brazil and four bands of higher rainfall accumulation over the Amazon. Noteworthy is the precipitation band over the Atlantic Ocean that extends to over the region of higher rainfall accumulation. The sequence of CMPORPH hourly rainfall accumulation fields (not shown) indicates that a cold front was moving north-eastward during the time span of the organized convection. As it moved northward, it confined moist north of it and produced gravity waves that in phase with the moist convergence over Northeast Brazil, triggered the organized convection that moved to a more favorable environmental moist static energy in west Amazon. Also important, the absence of the low level jet in its regular position further west near the Andes Cordillera.

An early spring instance of slow westward moving short-lived organized convection is depicted in Figure 8. The Hovmöller diagram of Figure 8(a) shows streaks of convection confined to $-45^{\circ}$ to $-80^{\circ}$ Longitude, given the South Atlantic high-pressure system over Northeast Brazil (not shown). Precipitation is more wide spread

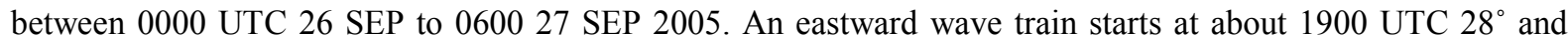
$-65^{\circ}$ Longitude and moves to $1200 \mathrm{UTC} 30^{\circ}$ and $-45^{\circ}$ longitude. As it pushes eastward individual streaks of convection move westward with slower speed compared to the wave train. The Hovmöller diagram of meridional winds at $850 \mathrm{hPa}$ shown in Figure 8(b) indicates a high-pressure system circulation with a center close to $-50^{\circ}$ Longitude between 27 to 31 SEP 2005. On the other hand, time-longitude $500 \mathrm{hPa}$ zonal winds in Figure 8(c) shows a wave train on northerly winds moving eastward in phase with the precipitation wave train in Figure 8(a). The average $850 \mathrm{hPa}$ wind field and 1-hour precipitation between 26 to $31 \mathrm{SEP} 2005$ are shown in Figure 8(d) and Figure 8(e). Easterlies advection of Equatorial moisture (not shown) between the Equator and $-15^{\circ}$ Latitude produced wide spread precipitation over west Amazon early in the episode and later the low level jet (Figure 8(d)) in conjunction with the upper level Southerly meridional wind system (Figure 8(c)) yield the wave train that suggest a Kelvin wave type of a system under drier conditions of early spring (Figure 8(e)). By mid spring in 2005, a much more consistent pattern of longer westward propagating convective system is observed in Figure 9(a). The systems started it development at $-50^{\circ}$ Longitude where $850 \mathrm{hPa}$ zonal winds inten- 


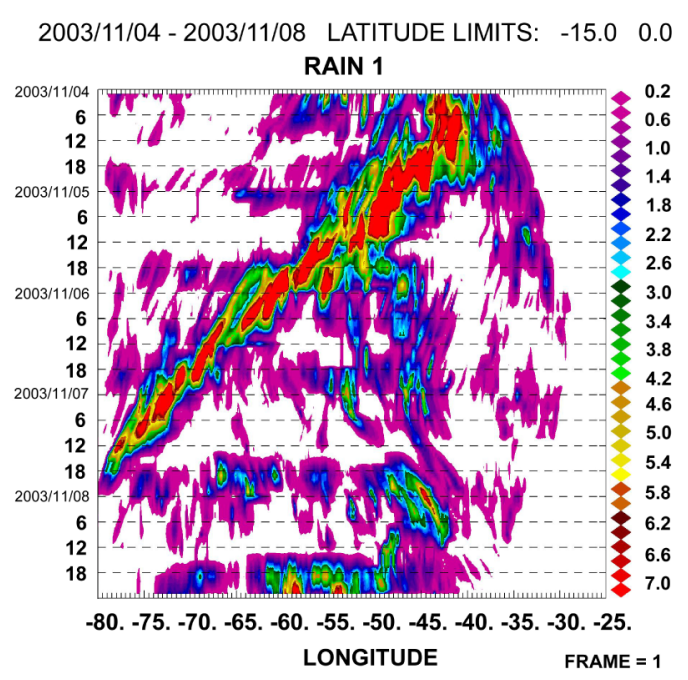

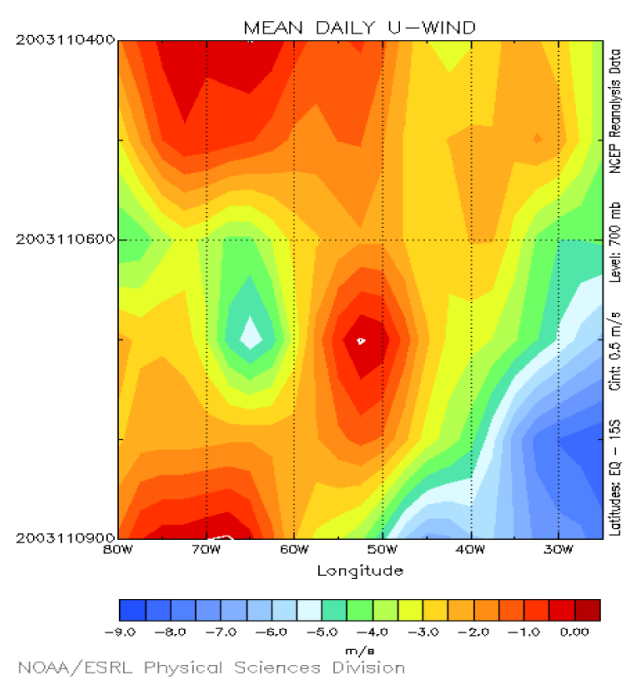

(b)

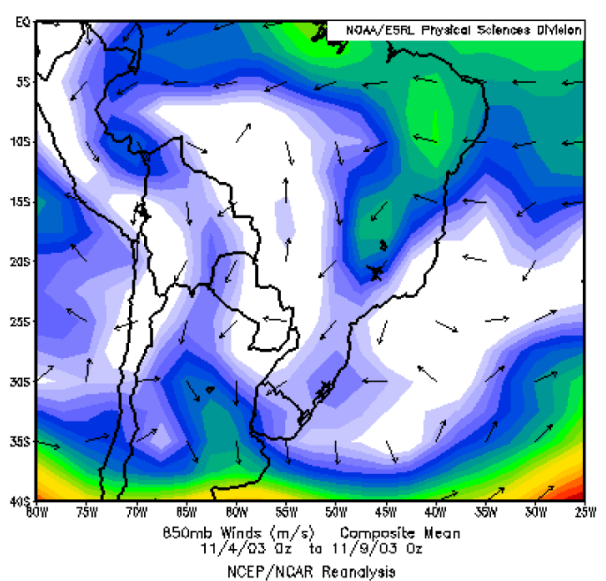

(d)

(a)

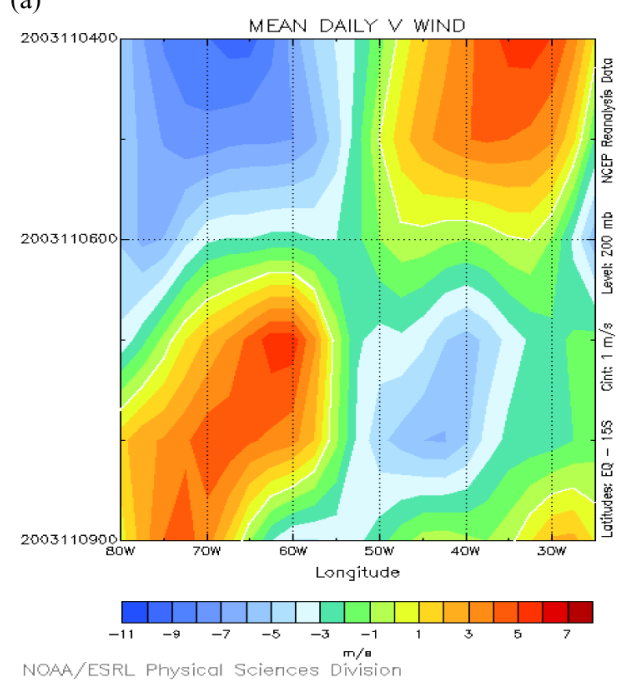

(c)

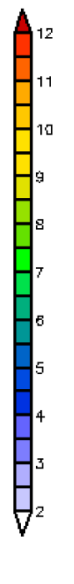

2003/11/04 - 2003/11/08 TIME LIMITS: 0.024 .0

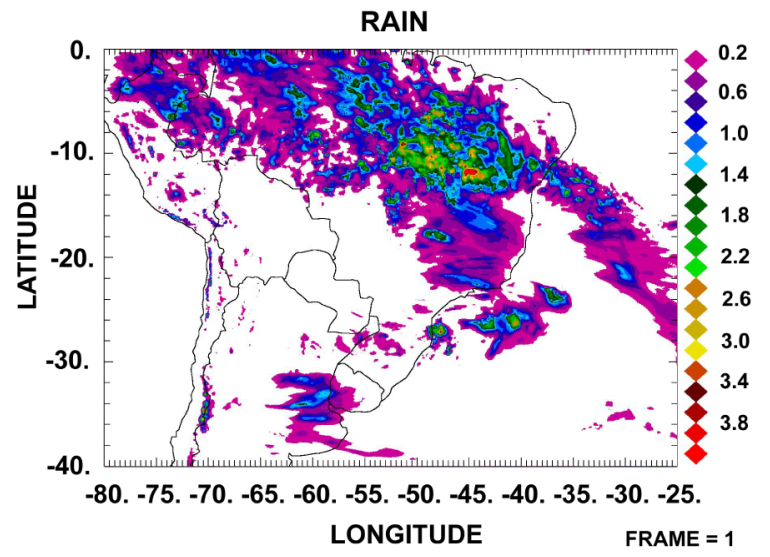

(e)

Figure 7. Episodes of organized convection between 04 and 09 March 2003. It shows Hovmöller diagrams of one-hour rainfall accumulation $\left(\mathrm{mm} \cdot \mathrm{hr}^{-1}\right.$ ) (a), 700-hPa zonal wind (b) and 200-hPa meridional wind fields (c), and averages of $850-\mathrm{hPa}$ wind (d) field and of hourly precipitation (e). Longitudes, latitudes, geographic contours, and color scales are indicated. 


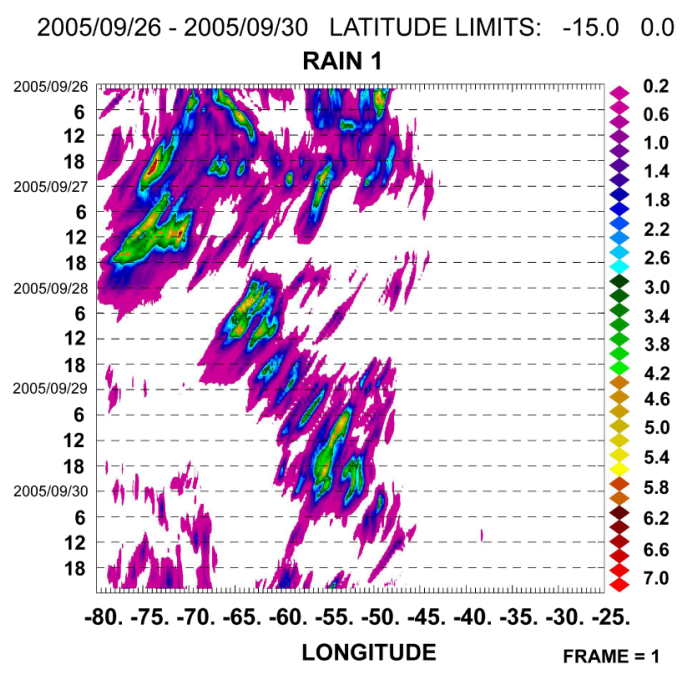

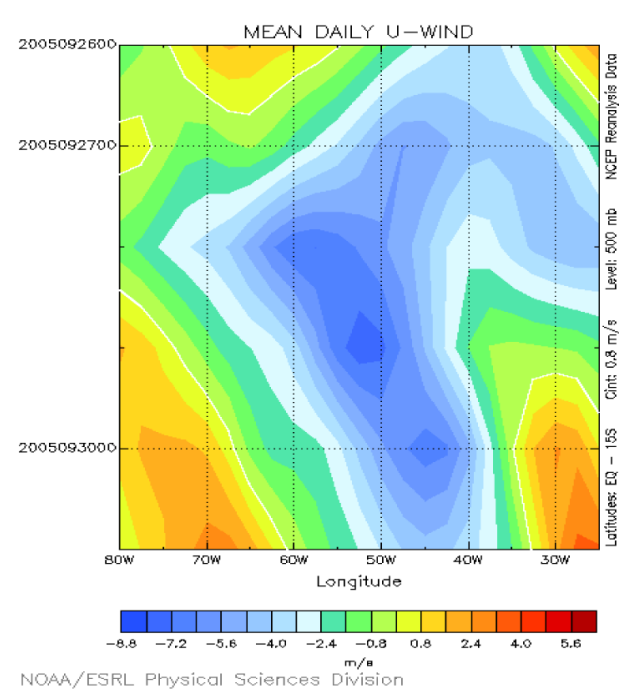

(b)

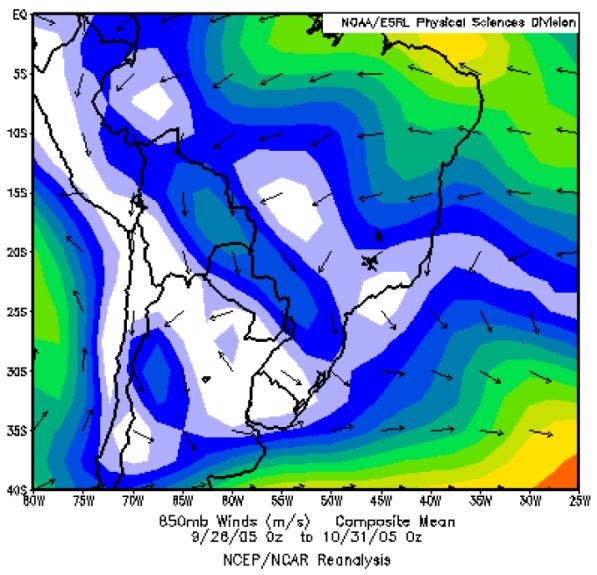

(d)

(a)

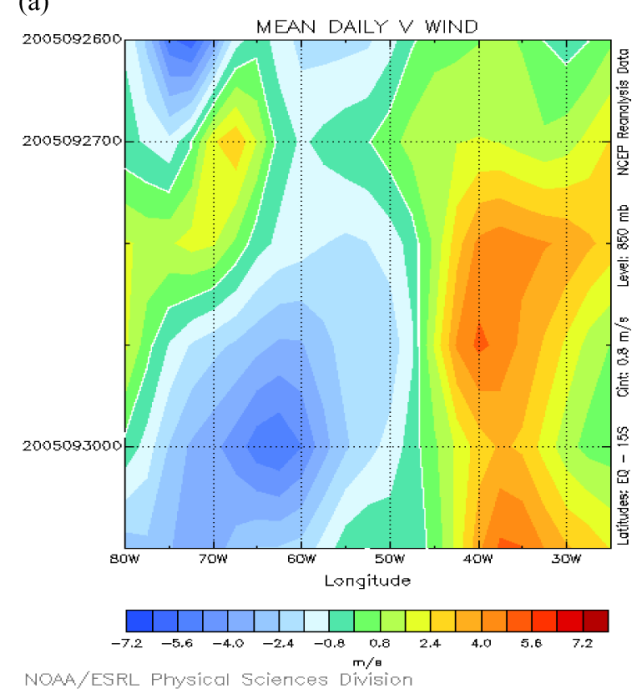

(c)
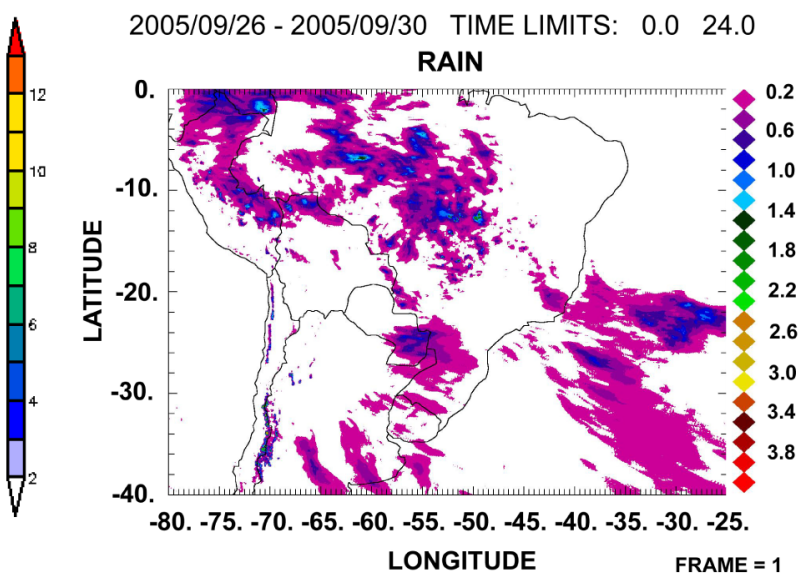

(e)

Figure 8. Episodes of organized convection between 26 and 30 September 2005. It shows Hovmöller diagrams of one-hour rainfall accumulation $\left(\mathrm{mm} \cdot \mathrm{hr}^{-1}\right)(\mathrm{a}), 850-\mathrm{hPa}$ meridional wind (b) and $500-\mathrm{hPa}$ zonal wind fields (c), and averages of 850 $\mathrm{hPa}$-wind (d) field and of hourly precipitation (e). Longitudes, latitudes, geographic contours, and color scales are indicated. 
sities (Figure 9(b)) were about $5 \mathrm{~m} \cdot \mathrm{s}^{-1}$ near the Northern Coast of Brazil induce by direct thermal circulations that induced a super sea breeze circulation in general in mid afternoon. There are many instances of squall lines that form over the coast and move in land with average speed of $12 \mathrm{~m} \cdot \mathrm{s}^{-1}$. The Hovmöller diagram of $500 \mathrm{hPa}$ meridional winds in the domain shown in Figure 9(c) indicates a series of wave trains all moving westward, a sequence of high and low systems. Southerly meridional wind wave trains are associated with the rainfall streaks (Figure 9(a)) while northerly meridional winds with the observed precipitation break period. During this period, even the diurnal cycle of convection (1800 UTC to 0000 UTC) is almost completely suppressed. Figure 9(d) and Figure 9(e) show the average $850 \mathrm{hPa}$ wind field and 1-hour precipitation between 2 and 7 SEP 2005. Equatorial Easterlies were more intense in general and the average hourly precipitation less structured or less contiguous, apparently. This might suggest a discrete propagation of precipitation that was forced by inertiagravitational waves. Nevertheless, the areas of higher rainfall accumulation are parallel to the convergence line near the surface (Figure 9(d)).

An instance of strong diurnal cycle under weak large scale forcing is given in Figure 10. The time-longitude diagram of precipitation shown in Figure 10(a) shows time lines when convection occurs at all longitudes center at 1800 UTC, more organized westward on 11 and 12 NOV and Eastward on 13 and 14 NOV 2015 together with some stationary features at about $-65^{\circ}$ and $-60^{\circ}$ West. Zonal winds were prevailing from Eastward (Figure 10(b)). An upper level low-pressure system associated to a cold front to the southeast is seeing in Figure 10(c) had little effect on the diurnal cycle. It became stationary over the Atlantic Ocean at about 0000 UTC on 14 NOV 2005 and produced a region of reactively low precipitation accumulation in between $-40^{\circ}$ and $-35^{\circ}$ Longitudes (Figure 10(a) and Figure 10(e)). The average 850-hPa wind field shown in Figure 10(d) shows a strong zonal wind channel near the Equator with a not so well defined Low Level Jet. Thus, this three instances a few days apart indicates a myriad of dynamic features leading to eastward and westward propagating convective systems as well more stationary systems caused by diurnal heating and transient systems propagating from south. It is apparent the interaction between the diurnal cycle of convective with Equatorial waves types that interlace with each other to yield complex patterns trough the year. Rainfall accumulations depend on moisture supply by the Easterlies but also by the Rainfall Forest.

The organization of the propagation of different convective clusters can be considered a consequence of the constance of the phase velocity of the Kelvin waves, due to the associated linear relation between the frequency and the wave number. For large wave numbers (i.e., small wave lengths), the associated frequency of Kelvin wave is large [19]. Therefore, for small scale convective systems, the frequency is likely increased, which can generate complex features of the convection distribution and rainfall patterns.

An instance of winter convective features over the Amazon Basin is shown in Figure 11 for 10-14 June 2006. The precipitation Hovmöller diagram in Figure 11(a) shows a much weaker diurnal cycle of convection (stationary line centred at 1800 UTC), slower westward propagating streaks of rainfall and almost stationary precipitation over the Atlantic Ocean. The later association with rain bands termed easterlies waves. Corresponding time-longitude diagrams of $850 \mathrm{hPa}$ zonal winds (Figure 11(b)) and $500 \mathrm{hPa}$ meridional winds (Figure 11(c)) indicate weaker low-level Easterlies and stronger upper level transients propagating westward. The average 850-hPa wind field (Figure 11(d)) shows a broader band of weaker Easterlies throughout the Latitudinal domain. Figure 11(e) shows the average hourly rainfall for the entire episode when convection was confined to near the Equator region as the ITCZ is displaced northward. Thus the winter is dominated by westward propagating features rather than in spring and summer. A complete statistics of westward and eastward propagating organized convection between 2002 and 2008 will be presented in Section 6. The instances sown in this section are to illustrate major characteristics of organized convection over the Amazon Basin.

\section{Diurnal Cycle of Convection}

The diurnal cycle of convection is illustrated with the rainfall date for 2005. Figure 12 shows the time-longitude diagram for two full diurnal cycles. Time-longitude high precipitation is observed over the Amazon Basin between $1800 \mathrm{UTC}$ and $2300 \mathrm{UTC}$ and between $-72^{\circ}$ and $-58^{\circ}$ Longitudes. It coincides with the lowest elevation of the watershed upstream from bifurcation of the Solimões and Negro Rivers. A much smaller maximum occurs at about $0600 \mathrm{UTC}$ and $-70^{\circ}$ Longitude associated with the Andes Mountain range. Slow propagating features tend to be confined from $-55^{\circ}$ to $-35^{\circ}$ Longitudes. Minima precipitation is observed in the morning hours 


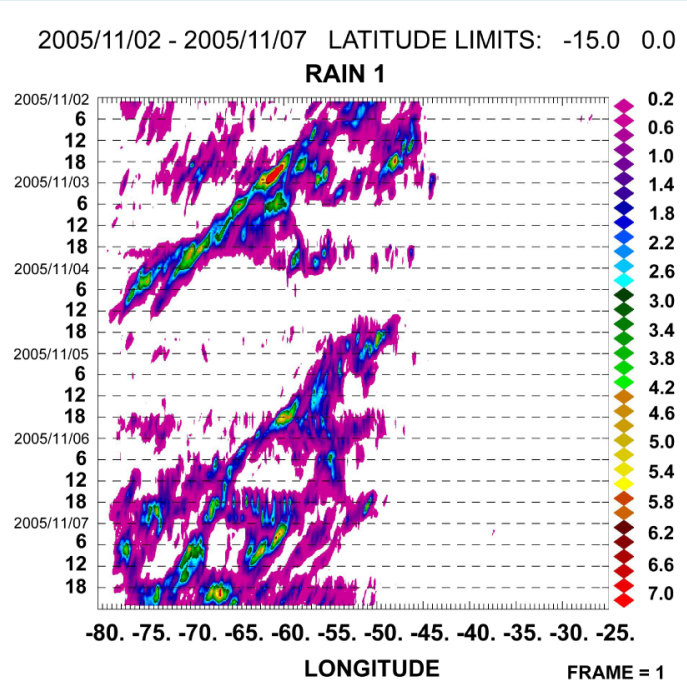

(a)
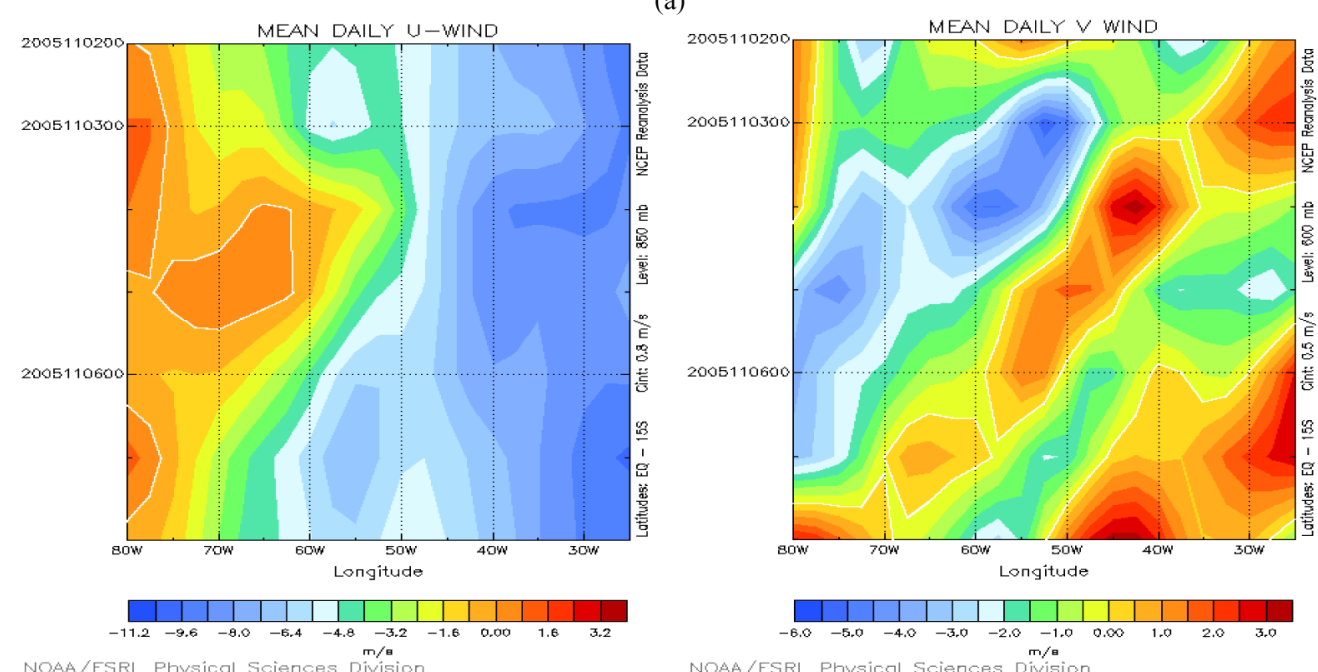

(c)

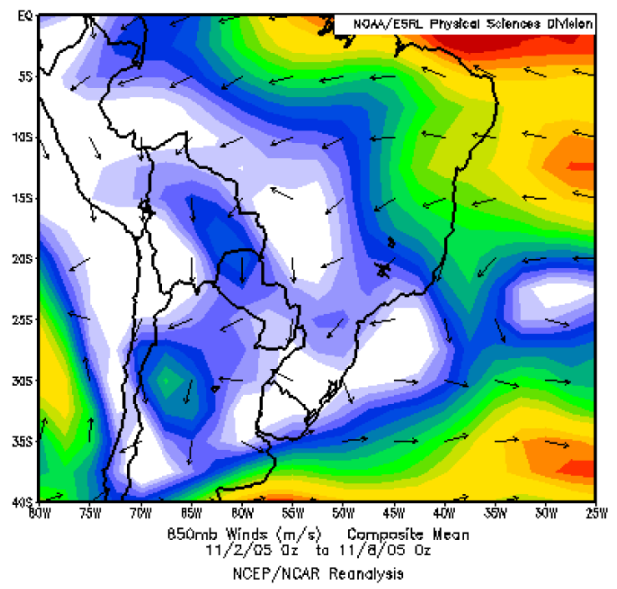

(d)
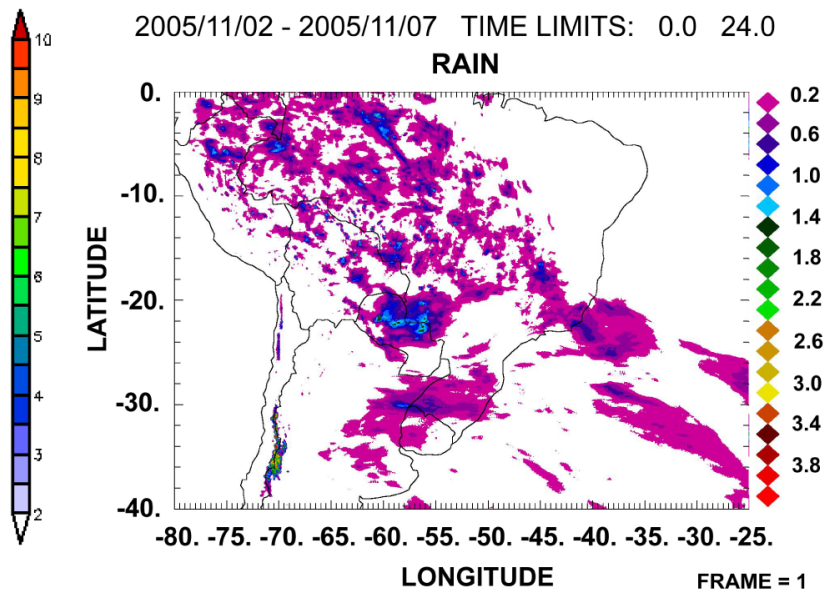

(e)

Figure 9. Episodes of organized convection between 02 and 07 November 2005. It shows Hovmöller diagrams of one-hour rainfall accumulation $\left(\mathrm{mm} \cdot \mathrm{hr}^{-1}\right)(\mathrm{a}), 850-\mathrm{hPa}$ meridional wind (b) and 600-hPa zonal wind fields (c), and averages of 850 $\mathrm{hPa}-w i n d(\mathrm{~d})$ field and of hourly precipitation (e). Longitudes, latitudes, geographic contours, and color scales are indicated. 


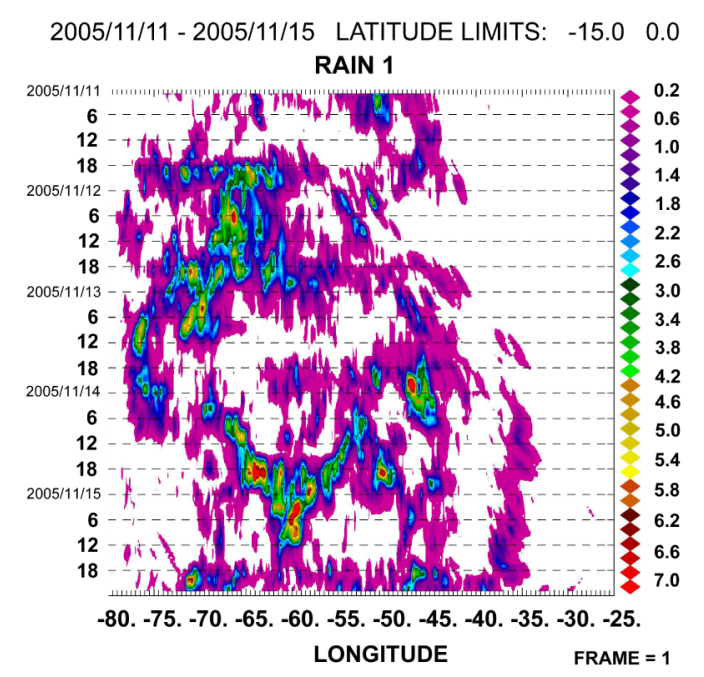

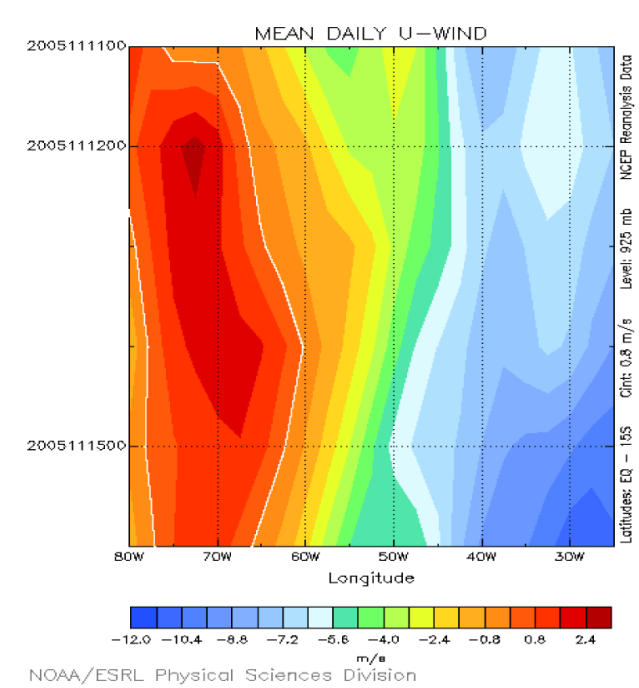

(b)

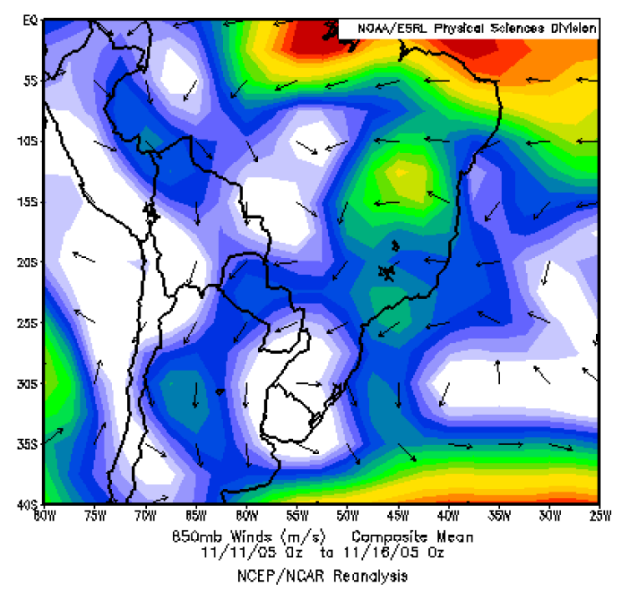

(d) (a)

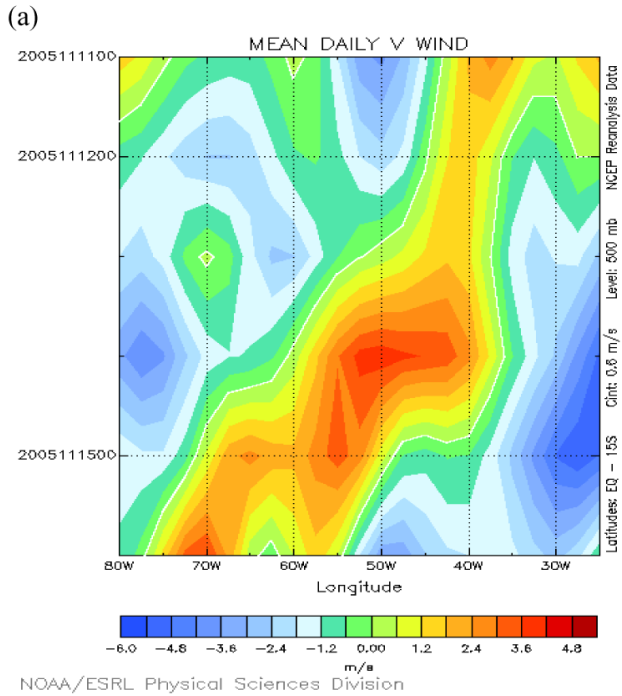

(c)
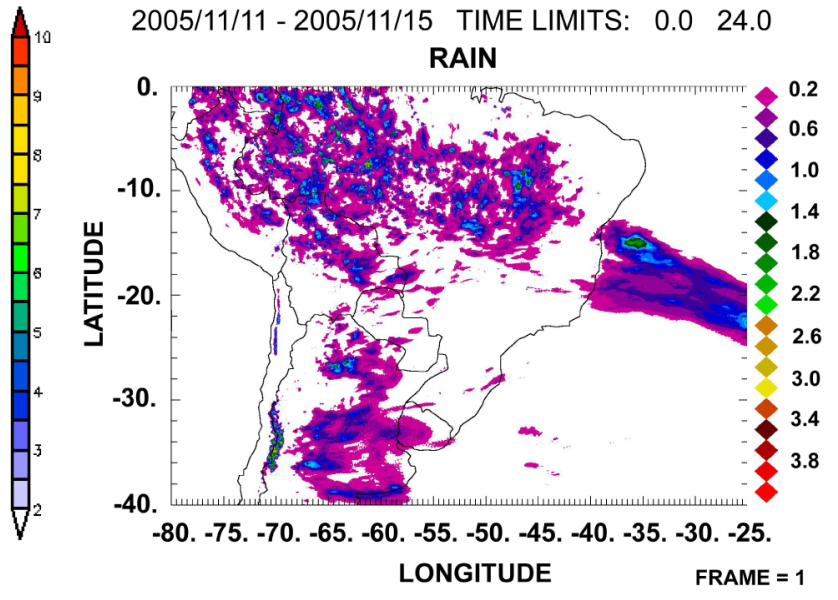

(e)

Figure 10. Episodes of organized convection between 11 and 15 November 2005. It shows Hovmöller diagrams of one-hour rainfall accumulation $\left(\mathrm{mm} \cdot \mathrm{hr}^{-1}\right)(\mathrm{a}), 925-\mathrm{hPa}$ meridional wind (b) and $600-\mathrm{hPa}$ zonal wind fields (c), and averages of 850 $\mathrm{hPa}$-wind (d) field and of hourly precipitation (e). Longitudes, latitudes, geographic contours, and color scales are indicated. 


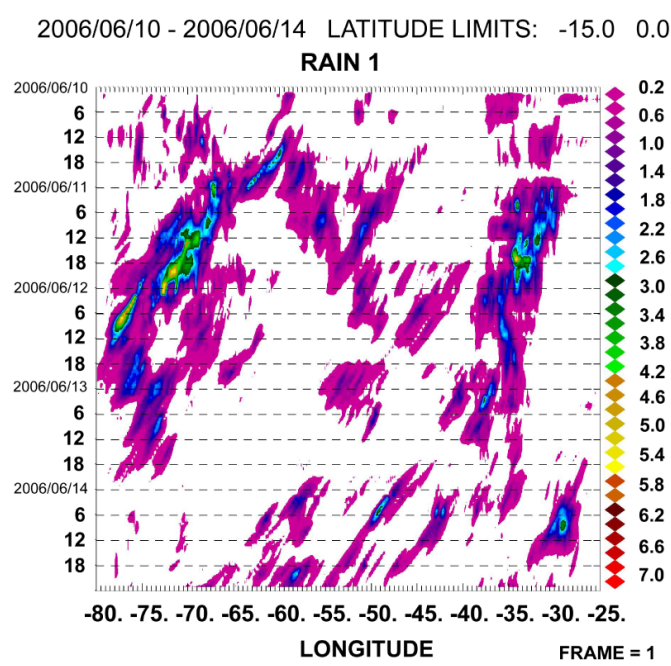

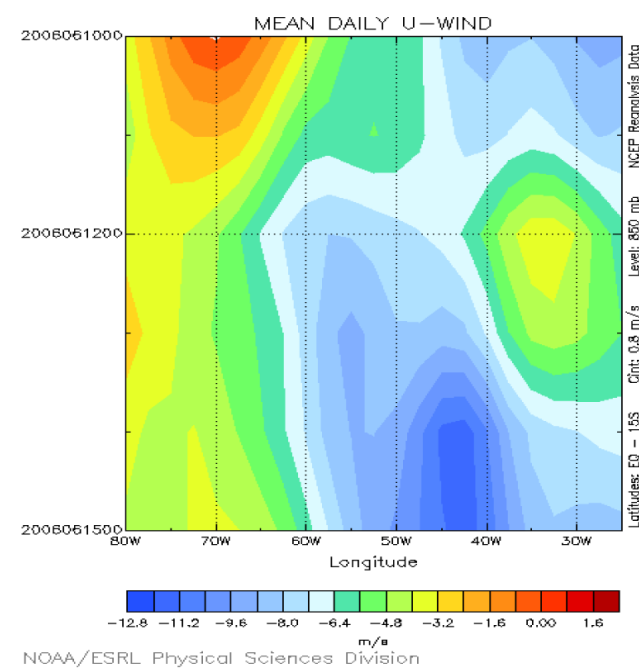

(b)

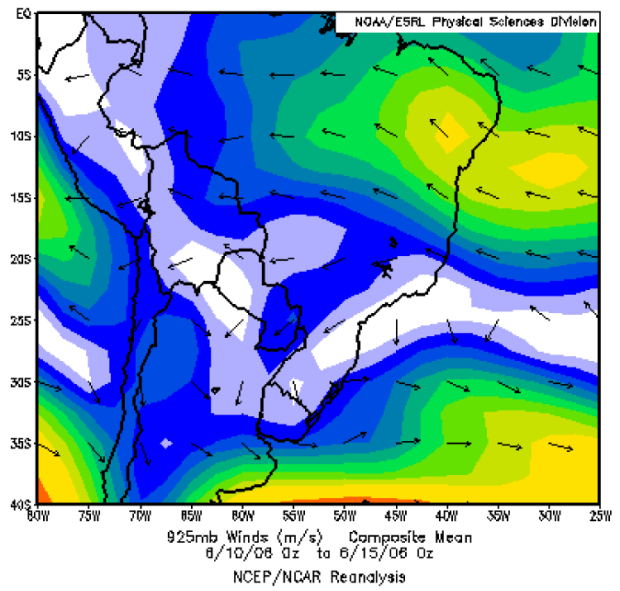

(d) (a)

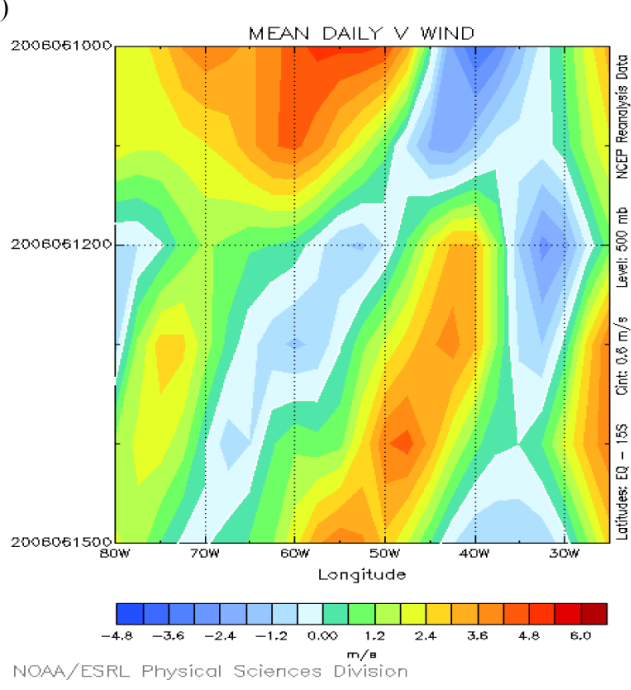

(c)

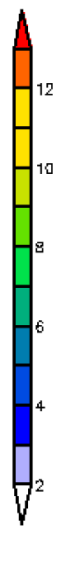

2006/06/10 - 2006/06/14 TIME LIMITS: 0.024 .0

RAIN

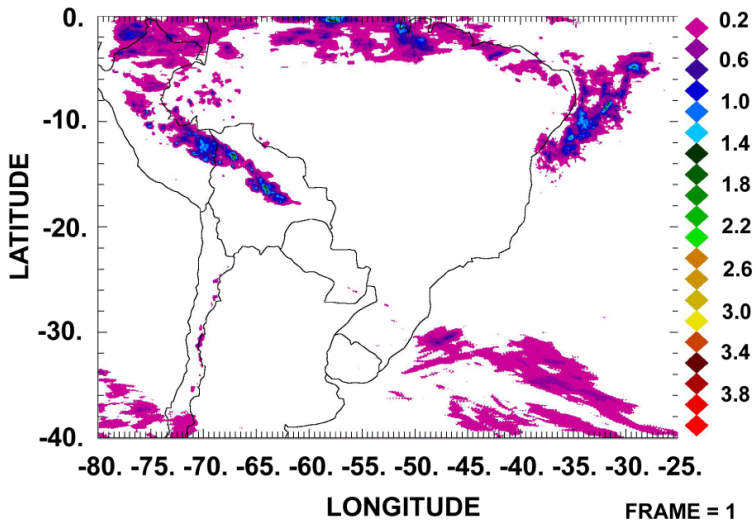

(e)

Figure 11. Episodes of organized convection between 02 and 07 November 2005. It shows Hovmöller diagrams of one-hour rainfall accumulation $\left(\mathrm{mm} \cdot \mathrm{hr}^{-1}\right)(\mathrm{a}), 850$-hPa meridional wind (b) and $600-\mathrm{hPa}$ zonal wind fields (c), and averages of 925$\mathrm{hPa}$ wind (d) field and of hourly precipitation (e). Longitudes, latitudes, geographic contours, and color scales are indicated. 


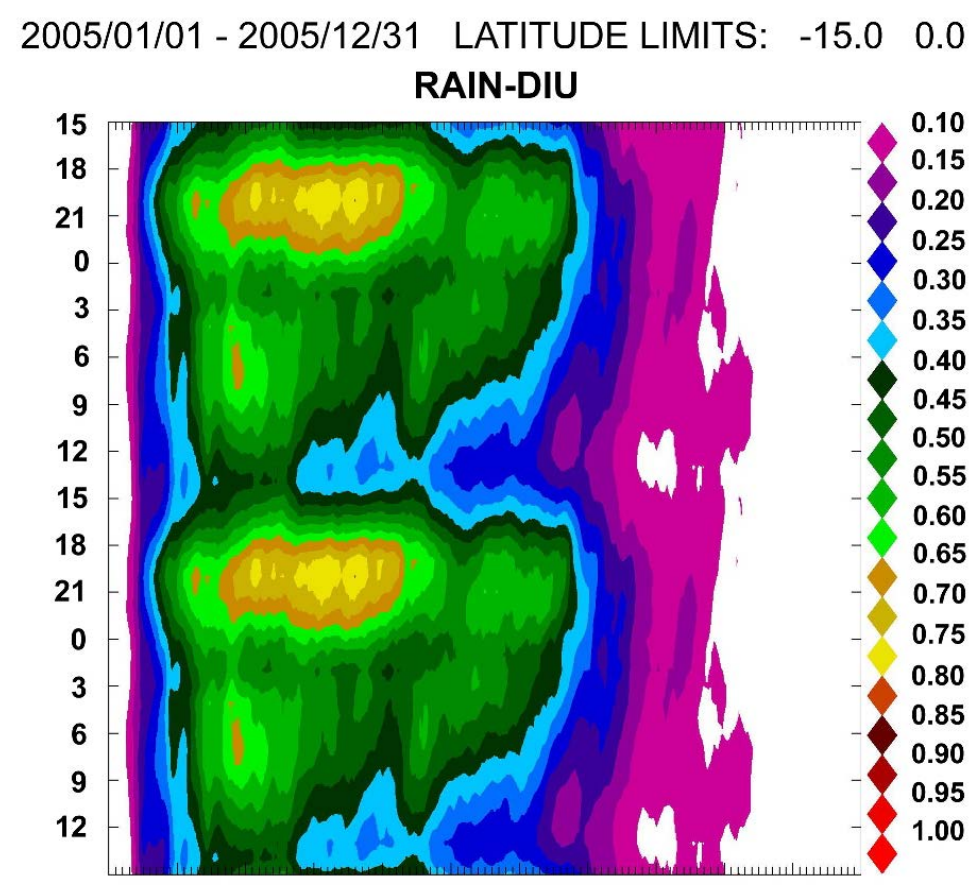

-80 . -75 . -70 . -65 . -60 . -55 . $-50 .-45 .-40 .-35 .-30 .-25$.

LONGITUDE

FRAME $=1$
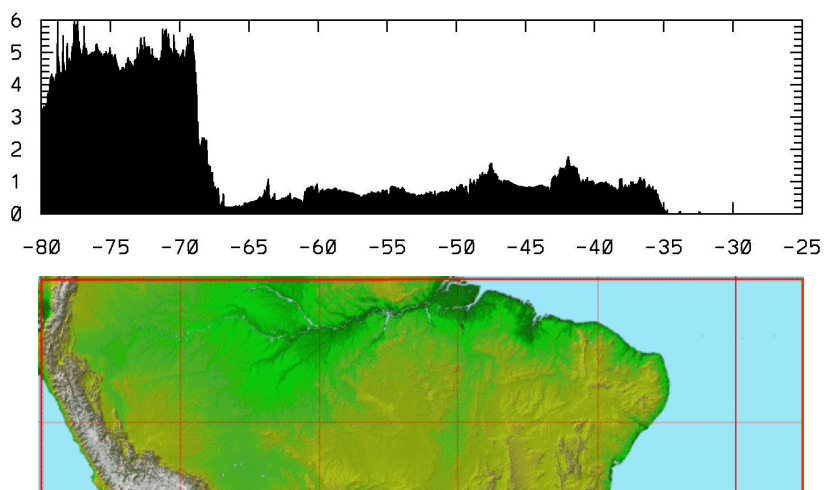

Figure 12. Hovmöller time-longitude diagram for one-hour $(\times 100$ UTC) rainfall accumulation average in a 48 -hr period computed with CMPORH rainfall estimation in the Amazon Basin domain for 2005. Longitudes, times, geographic contours, altitudes and color scales are indicated.

and eastward longitudes given less high moist static stability and the South Atlantic high-pressure system over Northeast Brazil.

The seasonal variation of the diurnal cycle of convection is shown in Figure 13 for the percentage of time with precipitation in the domain during winter (JUN-AGO), spring (SEP-NOV), summer (JAN-FEB) and fall (MAR-MAY) of 2005. The seasonal changes are remarkable with significant amplitude and phase differences through seasons. The frequency of hourly rainfall is highest and maximum of $80 \%$ in summer within a wide longitudinal range while in winter it is lowest and maximum of 30\% in western Amazon Basin. The diurnal cycle during fall resembles the summer one but with lower frequencies with a small maximum region of $60 \%$. The first peak in the diurnal cycle between 1800 UTC to 2300 UTC in spring is very well defined while the secondary maximum in frequency between 0300 and 0900 UTC virtually disappears. Low frequencies of hourly rainfall accumulation are in general small between $-45^{\circ}$ and $-25^{\circ}$ longitudes with a relative maximum of $20 \%$ in fall and absolute minimum in spring. Thus, in general, diabatic heating and evapotranspiration are major rain- 


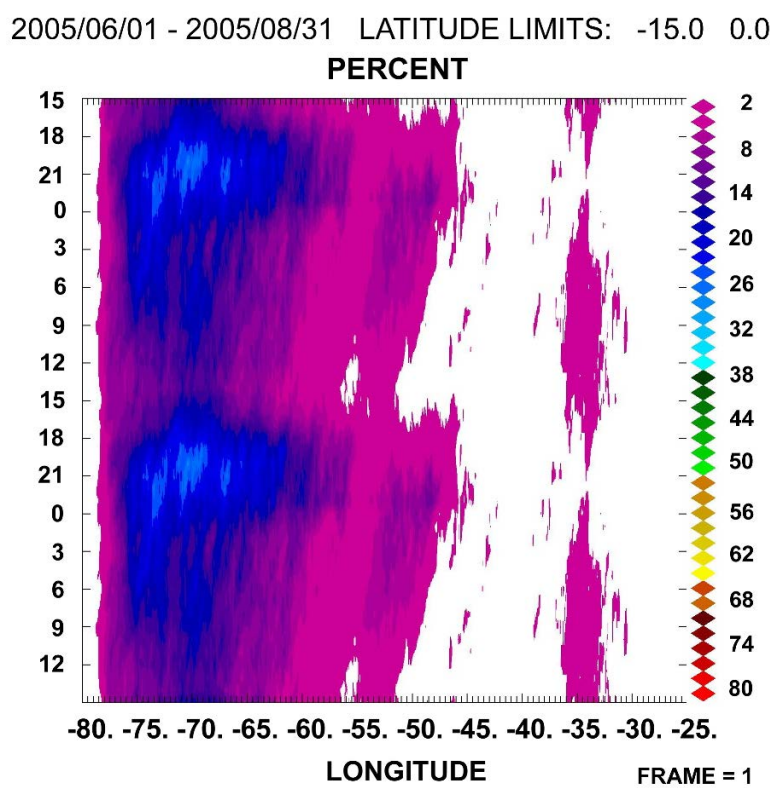

(a)

2005/01/01 - 2005/02/28 LATITUDE LIMITS: -15.0 0.0 PERCENT

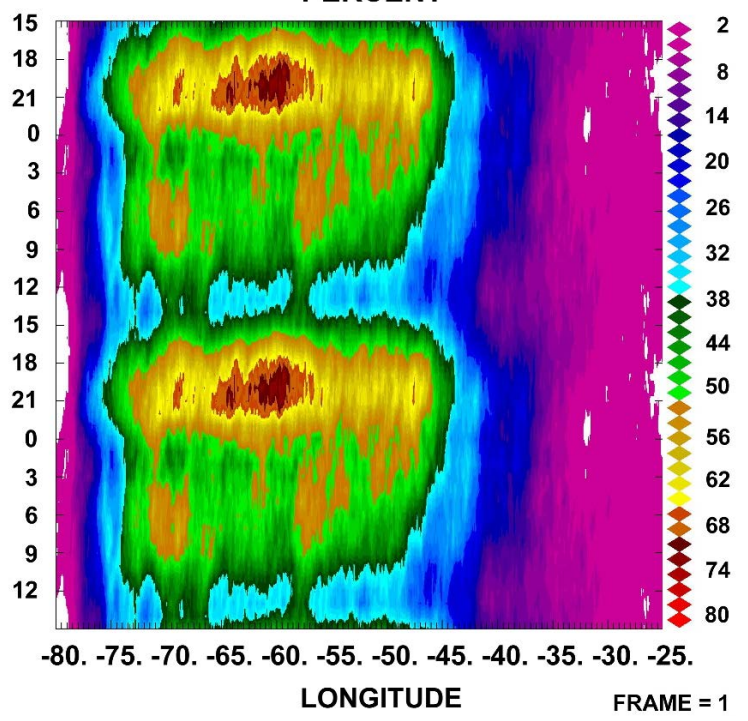

(c)
2005/09/01 - 2005/11/30 LATITUDE LIMITS: -15.0 0.0

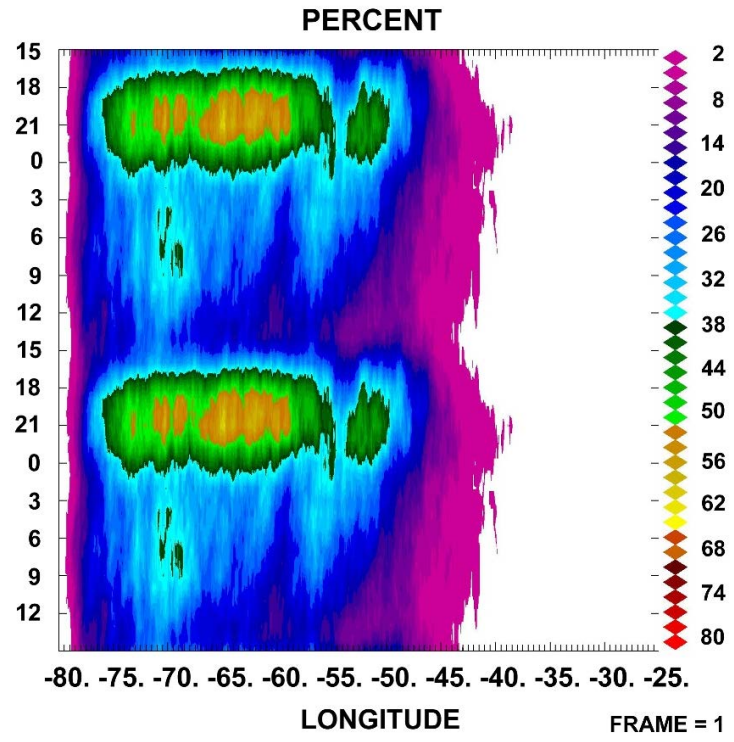

(b)

2005/03/01 - 2005/05/31 LATITUDE LIMITS: -15.0 0.0 PERCENT

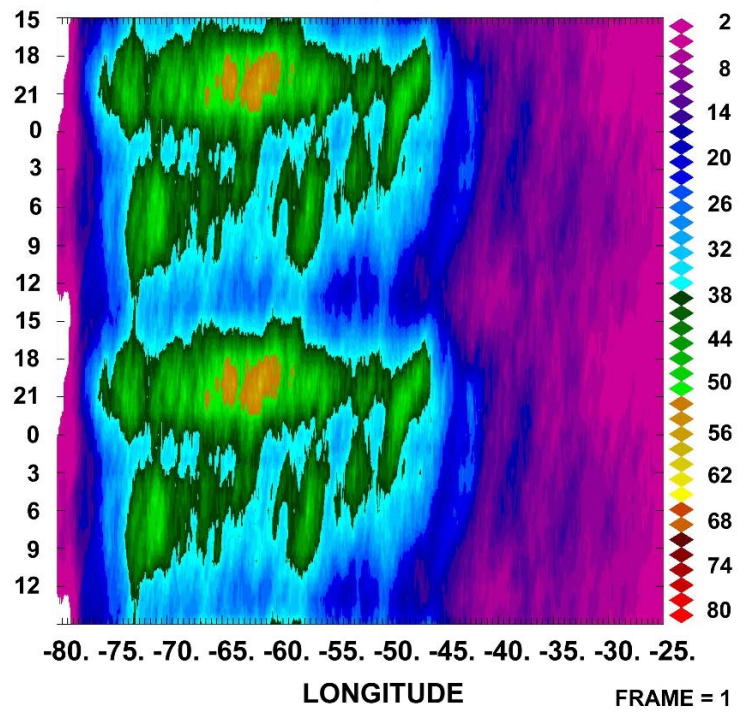

(d)

Figure 13. Similar to Figure 12 but for winter (a), spring (b), summer (c) and fall (d).

fall producing thermodynamic forcing that can be affected by all types of atmospheric waves from gravity to inertial and Kelvin waves. The exclusive source of moisture to the Amazon Basin is the Atlantic Ocean and it recycles its moisture by large amounts of evapotranspiration within its Rainforest.

The existing dynamic waves over the Amazon Basin organized the convection, its longevity and strength but in such rich moisture region and with very strong diurnal cycle, their overall contribution is in determining the phase of the convective systems. The instances of organized convection shown in Section 4, it is remarkable that convection organized by different dynamic mechanism at different space and time scales are secondary to the diurnal diabatic heat and moisture provided by evapotranspiration. Seemingly, the dynamic contribution of different types of waves is on phase speeds of organized convection as well as on lower boundary moisture fluxes by the Easterlies. In fact, residual evapotranspiration are advected to higher latitudes of South America by the 
low level jet. It produces a secondary rainfall maximum over the La Plata basin (Figure 2).

\section{Span, Phase Speed and Duration Statistics}

The number of episodes in the Amazon is fairly well distributed through all years with a total of 12.302 . The number of episodes in the Amazon Basin is maximum in January and minimum in August in spite of intraseasonal and inter-annual relative frequency fluctuations. Figure 14 shows the frequency distributions of duration (h), phase speed $\left(\mathrm{m}^{-\mathrm{s}^{-1}}\right)$, and span $(\mathrm{km})$ for all episodes of organized convection in the Amazon between December 2002 and June 2008. The relative frequency of duration and spans are similar with greater frequency of smaller episodes in Amazon. Phase speed frequency distributions in both basins are different because, though smaller, a significant number of eastward propagating episodes were computed. Thus, the frequency of eastward propagating episodes of organized convection is significantly less than previously suggested by [6], though it is interesting to notice that the distribution of positive phase speeds in the Amazon and La Plata are similar which suggests fronts in the La Plata and eastward propagating systems in the Amazon might be correlated. Table 1 shows basic statistics for episodes of organized convection discriminated by Basin and direction of propagation. The average phase speeds are $-11.8,13.2$ and $13.0 \mathrm{~m} \cdot \mathrm{s}^{-1}$ for westward and eastward propagating episodes in the Amazon and in eastward ones in the La Plata Basin, respectively. The statistics of phase speeds of eastward propagating episodes in the Amazon are virtually the same as the ones in the La Plata Basin. Average durations are 14, 10 and $13 \mathrm{~h}$ and, spans 510, 390 and $564 \mathrm{~km}$, respectively. Maxima phase speed, duration and span are associated to westward propagating episodes of organized convection in the Amazon Basin, although, on average, the span of episodes in the Amazon Basin are smaller than the ones in the La Plata Basin [13]. Similar results have been found in Australia [20] and Africa [21]. The frequency of westward episodes in the Amazon $(87 \%)$ is dominant and so modulates the yearly rainfall accumulation.

Longer (shorter) spans episodes can propagate very fast (very slow) depending on the underlying dynamic and thermodynamic conditions. Similarly, the spectrum of phase speeds tend to be narrower (broader) for shorter (longer) durations and spans and, there are episodes of higher (lower) phase speed for longer (shorter) spans and durations.

Amazon westward propagating episodes starting in late evening and in the east (west) have faster (slower) phase speeds as well as those started in early afternoon and longitudes between $-60^{\circ} \mathrm{W}$ to $-40^{\circ} \mathrm{W}$. Over all, westward episodes phase speeds increase from east to west across the Amazon Basin. On the other hand, eastward episodes phase speeds increase from West to East in late afternoon and evening. Eastward episodes have similar distribution but with a evident maximum between 0300 to $0600 \mathrm{UTC}$ and longitudes between $-80^{\circ} \mathrm{W}$ to $-70^{\circ} \mathrm{W}$. Westward episodes in the Amazon Basin have average longer spans from $-40^{\circ} \mathrm{W}$ to $-50^{\circ} \mathrm{W}$ while eastward episodes from $-80^{\circ} \mathrm{W}$ to $-60^{\circ} \mathrm{W}$ at any time.

Figure 15 shows the frequency distribution of episodes as a function of the starting and ending longitude in the Amazon basin. It shows also the area of analyses for reference. There are two peaks in starting frequency; one between $-50^{\circ} \mathrm{W}$ to $-45^{\circ} \mathrm{W}$ and another between $-65^{\circ} \mathrm{W}$ to $-60^{\circ} \mathrm{W}$ near the outlet and mid part (Manaus City) of the Amazon Basin that corresponds to $40 \%$ of all episodes. On the other hand, the frequency of ending longitudes between $-80^{\circ} \mathrm{W}$ to $-60^{\circ} \mathrm{W}$ are more than $45 \%$ of the episodes. Also, frequencies increase westward as most episodes propagate in that direction.

Figure 16 shows the frequency distribution of starting times of episodes of organized convection in the Amazon Basin. Over the Amazon Basin, there are three peaks in stating times at 0100 UTC (4.3\%), 0800 UTC (7.9\%) and 1900 UTC (8.1\%). The two minima are at 1000 UTC (2.1\%) and 0000 UTC (1.5\%). Two secondary peaks and the minimum are at 1300 UTC (3.6\%), 1500 UTC (4.9\%) and 0000 UTC.

The frequency distribution of starting times against the span, duration and phase speed (not shown) have similar distributions for each increment of these variables, especially in the Amazon Basin. There is wider combination of spans and durations in the Amazon basin for longer spans and durations, but most episodes are small. Phase speeds and spans frequency distributions in the Amazon Basin were analyzed according to the month of the year. Phase speeds of westward episodes in the Amazon from $-20 \mathrm{~m} \cdot \mathrm{s}^{-1}$ to close to zero $\mathrm{m} \cdot \mathrm{s}^{-1}$ have greater frequency from December to June. Episodes with phase speeds below $-20 \mathrm{~m} \cdot \mathrm{s}^{-1}$ have frequency distribution much smaller in amplitude with a peak in February. Eastward episodes have much smaller though similar distribution according to phase speeds, but are not observed from June to August. Spans less than $1000 \mathrm{~km}$ have higher frequency between December and May. Spans above $1000 \mathrm{~km}$ have a higher frequency in February. The 

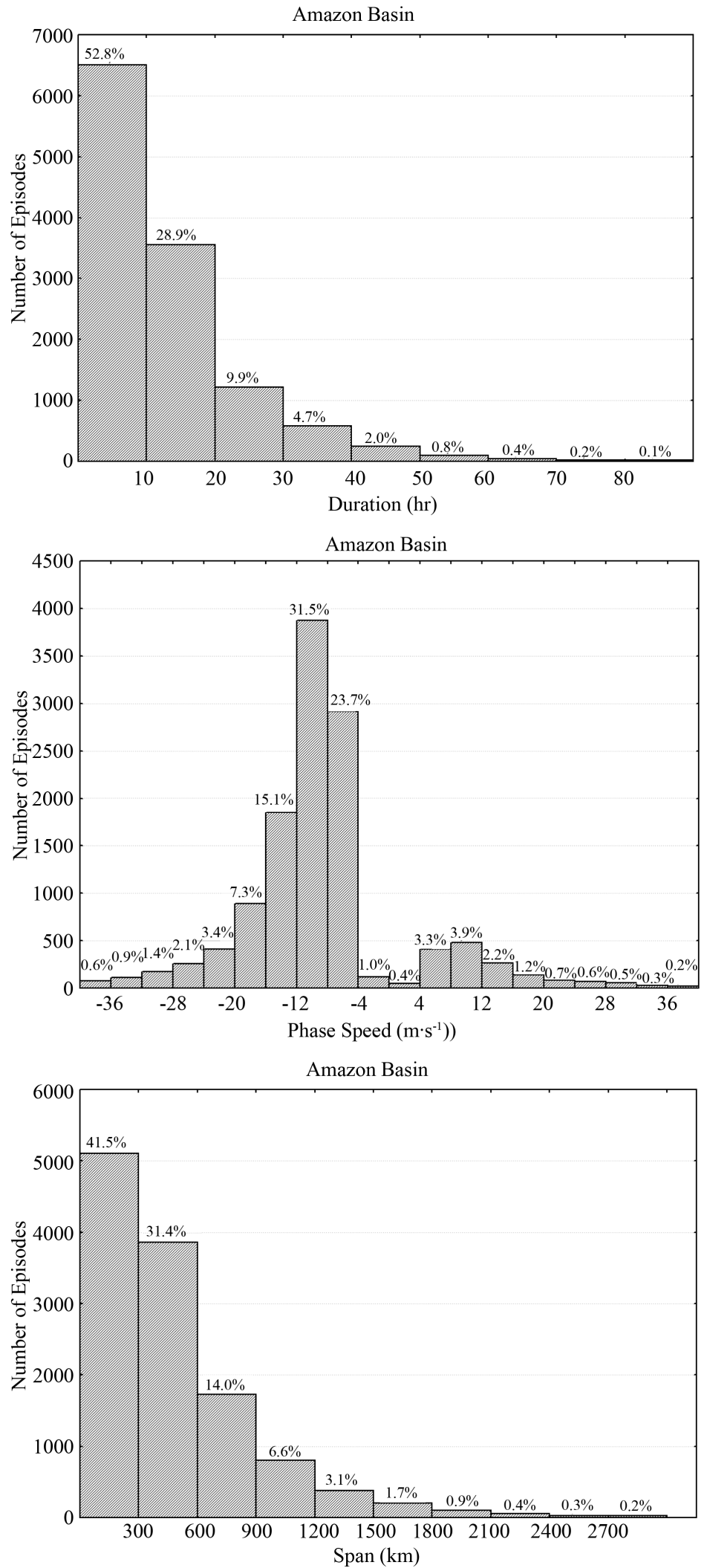

Figure 14. Frequency distribution of duration (top), phase speed (middle) and span (bottom) of episodes of organized convection in the Amazon basin between December 2002 and June 2008. 

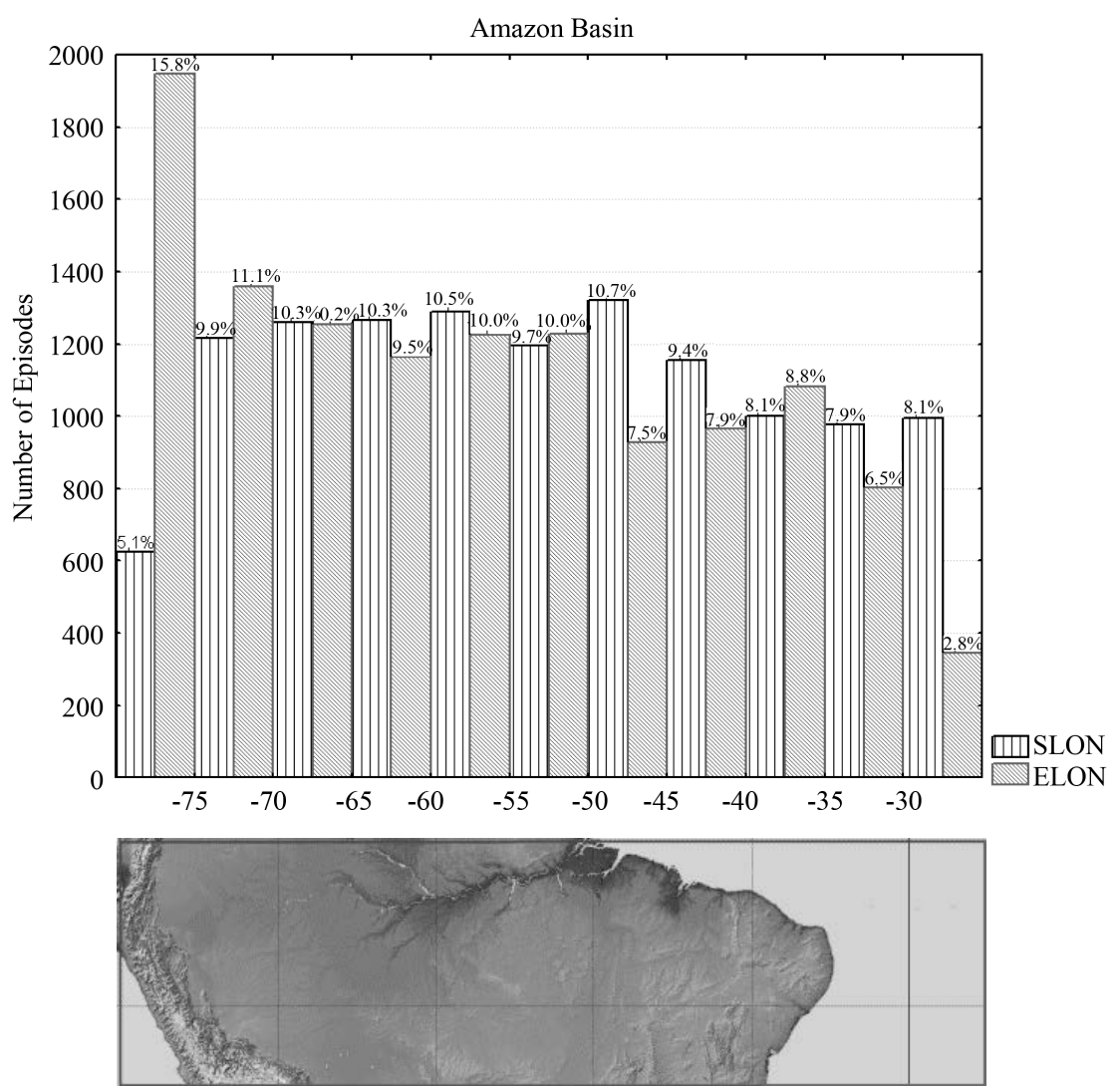

Figure 15. Frequency distribution of starting and ending longitudes $\left(^{\circ}\right)$ of organized convection in the Amazon Basin between December 2002 and June 2008.

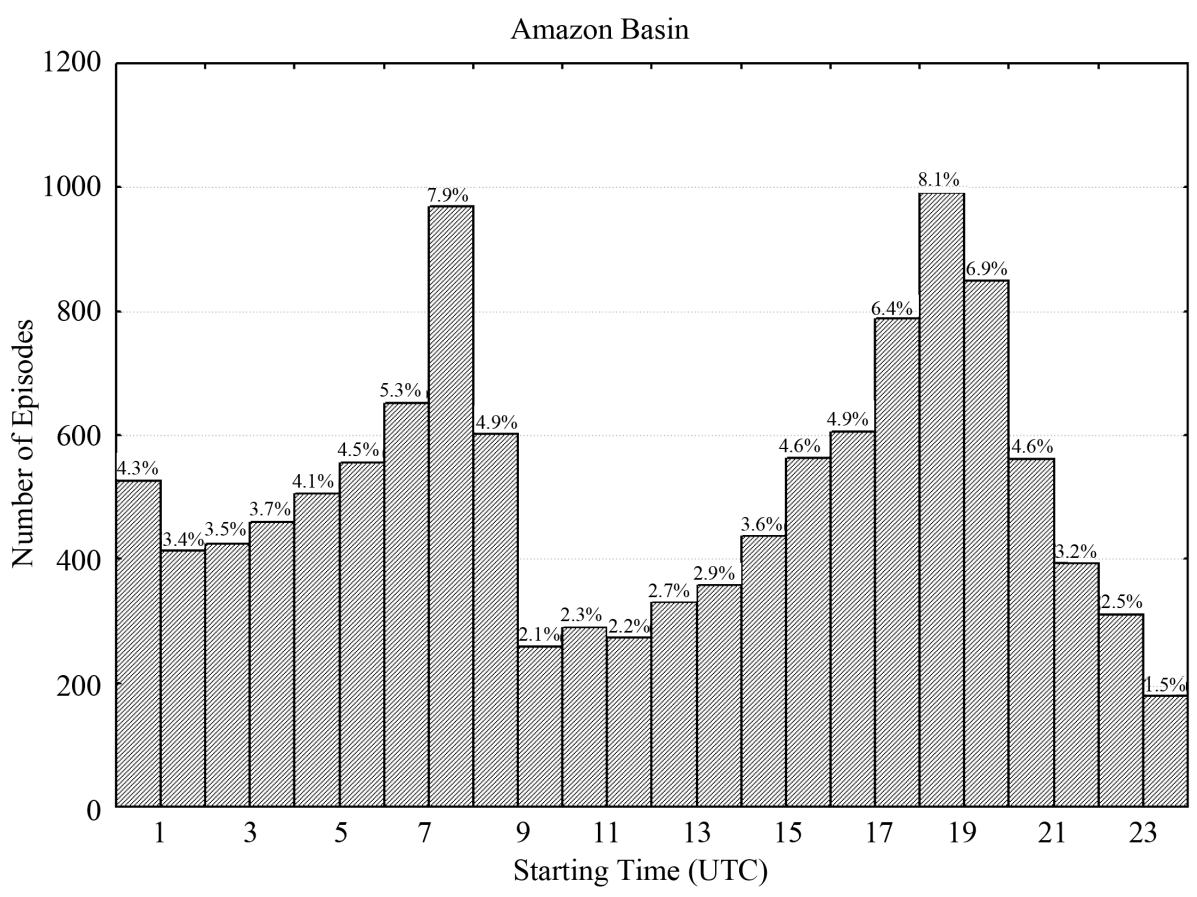

Figure 16. Frequency distribution of stating time (UTC) of organized convection in the Amazon between December 2002 and June 2008. 
ones above $2000 \mathrm{~km}$ tend to occur through the year with same probability for each month.

Table 1 and Table 2 summarize the span, duration, phase speed and recurrence of episodes of organized convection westward and eastward propagating systems, respectively. A total of 5061 and 616 westward and eastward propagating systems, respectively, were account for between 2002 and 2008. On average, westward propagating systems have longer spans $(559 \mathrm{~km})$, and longer duration (13.7 hours), while eastward ones have greater phase speeds $\left(16.8 \mathrm{~m} \cdot \mathrm{s}^{-1}\right)$. The westward propagation maximum span $(2616 \mathrm{~km})$, duration (62 hours) and phase speed $\left(-22.3 \mathrm{~m} \cdot \mathrm{s}^{-1}\right)$ occurs in fall season, while the eastward maximum span $(940 \mathrm{~km})$, duration (18 hours) and phase speed $\left(30.7 \mathrm{~m} \cdot \mathrm{s}^{-1}\right)$ occur in summer.

\section{Conclusions}

An unique satellite-derived rainfall estimation with very high spatial and temporal resolution was used to study the main characteristics of organized convection over the Amazon and La Plata Basins, two important water-

Table 1. Statistics of Westward convective rainfall episodes in the Amazon basin ( $-25 \mathrm{~W}$ to $-80 \mathrm{~W} ; 0 \mathrm{~S}$ to $-15 \mathrm{~S})$ between December 2003 and June 2008.

\begin{tabular}{|c|c|c|c|c|c|c|c|}
\hline \multicolumn{8}{|c|}{ WESTWARD } \\
\hline \multicolumn{8}{|c|}{ Annual (5061) } \\
\hline Recurrence Frequency & $1 /$ day & $2 /$ day & 1/week & $1 / 2$ week & $1 /$ month & Mean & Median \\
\hline Span $(\mathrm{km})$ & 544 & 878 & 1521 & 1886 & 2264 & 559 & 396 \\
\hline Duration (h) & 13.0 & 22.0 & 36.0 & 44.0 & 55.0 & 13.7 & 10.0 \\
\hline Phase Speed $\left(\mathrm{m} \cdot \mathrm{s}^{-1}\right)$ & -13.1 & -16.1 & -20.6 & -21.6 & -22.3 & -12.1 & -11.5 \\
\hline \multicolumn{8}{|c|}{ DJF (1242) } \\
\hline Recurrence Frequency & $1 /$ day & $2 /$ day & 1/week & $1 / 2$ week & $1 /$ month & Mean & Median \\
\hline Span (km) & 538 & 835 & 1435 & 1739 & 2152 & 542 & 383 \\
\hline Duration (h) & 13.0 & 22.0 & 36.0 & 44.0 & 57.0 & 13.6 & 9.0 \\
\hline Phase Speed $\left(\mathrm{m} \cdot \mathrm{s}^{-1}\right)$ & -12.9 & -16.4 & -20.6 & -21.6 & -22.3 & -12.0 & -11.1 \\
\hline \multicolumn{8}{|c|}{ MAM (1604) } \\
\hline Recurrence Frequency & $1 /$ day & $2 /$ day & 1/week & $1 / 2$ week & $1 /$ month & Mean & Median \\
\hline Span (km) & 736 & 1088 & 1744 & 2084 & 2616 & 609 & 439 \\
\hline Duration (h) & 18.0 & 28.0 & 41.0 & 51.0 & 62.0 & 14.9 & 11.0 \\
\hline Phase Speed $\left(\mathrm{m} \cdot \mathrm{s}^{-1}\right)$ & -14.0 & -16.9 & -20.8 & -21.8 & -22.3 & -12.0 & -11.4 \\
\hline \multicolumn{8}{|c|}{ JJA (1356) } \\
\hline Recurrence Frequency & 1/day & $2 /$ day & 1/week & $1 / 2$ week & $1 /$ month & Mean & Median \\
\hline Span $(\mathrm{km})$ & 526 & 823 & 1435 & 1725 & 2115 & 515 & 371 \\
\hline Duration (h) & 13.0 & 22.0 & 34.0 & 43.0 & 55.0 & 12.9 & 9.0 \\
\hline Phase Speed $\left(\mathrm{m} \cdot \mathrm{s}^{-1}\right)$ & -13.2 & -16.3 & -20.0 & -21.4 & -22.3 & -12.0 & -11.3 \\
\hline \multicolumn{8}{|c|}{ SON (859) } \\
\hline Recurrence Frequency & 1/day & $2 /$ day & 1/week & $1 / 2$ week & $1 /$ month & Mean & Median \\
\hline Span $(\mathrm{km})$ & 365 & 668 & 1398 & 1886 & 2226 & 563 & 390 \\
\hline Duration (h) & 8.0 & 15.0 & 30.0 & 38.0 & 46.0 & 12.7 & 9.0 \\
\hline Phase Speed $\left(\mathrm{m} \cdot \mathrm{s}^{-1}\right)$ & -12.0 & -15.5 & -20.4 & -21.7 & -22.3 & -12.9 & -12.4 \\
\hline
\end{tabular}


Table 2. Similar to Table 1, except for eastward episodes.

\begin{tabular}{|c|c|c|c|c|c|c|c|}
\hline \multicolumn{8}{|c|}{ EASTWARD } \\
\hline \multicolumn{8}{|c|}{ Annual (616) } \\
\hline Recurrence Frequency & $1 /$ day & 2/day & 1/week & $1 / 2$ week & $1 /$ month & Mean & Median \\
\hline Span $(\mathrm{km})$ & $\sim$ & $\sim$ & 334 & 513 & 699 & 379 & 297 \\
\hline Duration (h) & $\sim$ & $\sim$ & 6.0 & 8.0 & 12.0 & 6.7 & 5.0 \\
\hline Phase Speed $\left(\mathrm{m} \cdot \mathrm{s}^{-1}\right)$ & $\sim$ & $\sim$ & 16.9 & 22.3 & 27.5 & 16.8 & 15.5 \\
\hline \multicolumn{8}{|c|}{ DJF (243) } \\
\hline Recurrence Frequency & $1 /$ day & 2/day & $1 /$ week & $1 / 2$ week & $1 /$ month & Mean & Median \\
\hline Span $(\mathrm{km})$ & $\sim$ & 148 & 513 & 717 & 940 & 425 & 322 \\
\hline Duration (h) & $\sim$ & 3.0 & 9.0 & 12.0 & 18.0 & 7.4 & 6.0 \\
\hline Phase Speed $\left(\mathrm{m} \cdot \mathrm{s}^{-1}\right)$ & $\sim$ & 9.1 & 21.2 & 25.2 & 30.7 & 17 & 15.5 \\
\hline \multicolumn{8}{|c|}{ MAM (138) } \\
\hline Recurrence Frequency & $1 /$ day & $2 /$ day & $1 /$ week & $1 / 2$ week & $1 /$ month & Mean & Median \\
\hline Span $(\mathrm{km})$ & $\sim$ & $\sim$ & 303 & 452 & 649 & 366 & 291 \\
\hline Duration (h) & $\sim$ & $\sim$ & 5.0 & 8.0 & 12.0 & 6.8 & 5.0 \\
\hline Phase Speed $\left(\mathrm{m} \cdot \mathrm{s}^{-1}\right)$ & $\sim$ & $\sim$ & 16 & 20.6 & 26.6 & 16.5 & 15.5 \\
\hline \multicolumn{8}{|c|}{ JJA (75) } \\
\hline Recurrence Frequency & $1 /$ day & $2 /$ day & $1 /$ week & $1 / 2$ week & $1 /$ month & Mean & Median \\
\hline Span $(\mathrm{km})$ & $\sim$ & $\sim$ & 136 & 309 & 414 & 298 & 272 \\
\hline Duration (h) & $\sim$ & $\sim$ & 3.0 & 5.0 & 7.0 & 5.2 & 5.0 \\
\hline Phase Speed $\left(\mathrm{m} \cdot \mathrm{s}^{-1}\right)$ & $\sim$ & $\sim$ & 9.4 & 16.4 & 24.1 & 16.7 & 14.4 \\
\hline \multicolumn{8}{|c|}{ SON (160) } \\
\hline Recurrence Frequency & 1/day & 2/day & 1/week & $1 / 2$ week & $1 /$ month & Mean & Median \\
\hline Span $(\mathrm{km})$ & $\sim$ & $\sim$ & 328 & 476 & 674 & 358 & 297 \\
\hline Duration (h) & $\sim$ & $\sim$ & 5.0 & 8.0 & 11.0 & 6.2 & 5.0 \\
\hline Phase Speed $\left(\mathrm{m} \cdot \mathrm{s}^{-1}\right)$ & $\sim$ & $\sim$ & 16.6 & 22.8 & 28.8 & 16.7 & 14.9 \\
\hline
\end{tabular}

sheds in South America. The analysis of Hovmöller diagrams seems to indicate that the convective clusters present propagation in a similar way the expected to equatorial Kelvin waves (i.e., eastward). Meanwhile, the individual storms forming the cluster can propagate westward. Episodes of organized convection have been analyzed by means of time-longitude fields of rainfall accumulation and a technique to compute the starting and ending longitudes and times of them, respective phase speeds, spans and duration. Basic statistics have been obtained for more 12,000 episodes in the Amazon. It is dominated by westward episodes of organized convection with average span, duration and phase speed of $510 \mathrm{~km}, 14 \mathrm{hr}$ and $-12 \mathrm{~m} \cdot \mathrm{s}^{-1}$, respectively. Transient weather systems in the Southern South America may produce episodes of eastward propagation in the Amazon with similar phase speed but smaller duration and span on average. Phase speeds and span tend to be correlated to specific starting times and longitudes. Phase speeds tend to be higher at West and East of the domain for eastward and westward episodes in the Amazon, respectively.

In general, longer span westward episodes start at the outlet or in the middle of the Amazon Basin while eastward ones downstream from Andes Cordillera. Episodes starting times have three peaks in the Amazon related to the diurnal diabatic heating where transient systems such as cold fronts, frontogenesis and waves trigger by topography alter the diurnal cycle of convection. The quantity and complexity of episodes of organized convection in the Amazon is overwhelming but this current analysis indicates that time and space characteristics 
and their dynamic and thermodynamic environment can stratified. Likewise, the episodes of heavy precipitation seemed to be locked with topography and low level baroclinic features and inflow moisture from the Amazon. Surprisingly, higher westward phase speeds have increases while lower ones have decreased from 2003 to 2007.

The results obtained by CMORPH data analysis have shown that most episodes of organized convection tend to move westward across the Amazon Basin. Descriptive statistics indicate average phase speed of westward and eastward episodes of convection in the Amazon basin at $-11.8 \mathrm{~m} \cdot \mathrm{s}^{-1}$ and $13.0 \mathrm{~m} \cdot \mathrm{s}^{-1}$, respectively. Eastward propagating systems are influenced by northeastward moving cold fronts in Southern South America and tend to trigger and to organize convection across the Amazon Basin. Hourly rainfall analyses indicate that convection over the Amazon region is often organized. The CMORPH data set also allowed a quantitative evaluation of the intra-seasonal and inter-annual variations of rainfall accumulation and inter-annual variability of the diurnal cycle. CMOPRH data set can be applied for providing rapid cycles of actualization of the spatial/temporal rainfall distribution (i.e., in high resolution), as also a physically consistent way for obtaining the precipitation input for increasingly powered forecasting tools (i.e., specially for nowcasting), given both academically and operationally support, over regions with limited surface data, such as the huge Amazon Basin. Results presented in this work indicate that it might be possible to forecast rainfall in the Amazon at some spatial and temporal scales, proper to the higher convective systems found there [16].

\section{Acknowledgements}

The National Council for Scientific and Technological Development (CNPq) sponsored this research, under grant 302349/2014-6. The authors express their gratitude to their respective organizations for providing opportunities and means for this research. The authors are also thankful to CPC/NCEP for providing CMORPH datasets.

\section{References}

[1] Joyce, R.J., Janowiak, J.E., Arkin, P.A. and Xie, P. (2004) CMORPH: A Method that Produces Global Precipitation Estimates from Passive Microwave and Infrared Data at High Spatial and Temporal Resolution. Journal of Hydrometeorology, 5, 487-503. http://dx.doi.org/10.1175/1525-7541(2004)005<0487:CAMTPG >2.0.CO;2

[2] Negri, A.J., Agnostou, E.N. and Adler, R.F. (2000) A 10-Yr Climatology of Amazonian Rainfall Derived from Passive Microwave Satellite Observations. Journal of Applied Meteorology, 39, 42-56. http://dx.doi.org/10.1175/1520-0450(2000)039<0042:AYCOAR>2.0.CO;2

[3] Negri, A.J., Adler, R.F. and Xu, L. (2002) A TRMM-Calibrated Infrared Rainfall Algorithm Applied over Brazil. Journal of Geophysical Research, 107, 8084, 16-1, 15, LBA Special Issue.

[4] Garreaud, R.D. and Wallace, J.M. (1997) The Diurnal March of Convective Cloudiness over the Americas. Monthly Weather Review, 125, 3157-3171. http://dx.doi.org/10.1175/1520-0493(1997)125<3157:TDMOCC>2.0.CO;2

[5] Machado, L.A.T., Laurent, H., Dessay, N. and Miranda, I. (2004) Seasonal and Diurnal Variability of Convection over the Amazonia: A Comparison of Different Vegetation Types and Large Scale Forcing. Theoretical and Applied Climatology, 78, 61-77. http://dx.doi.org/10.1007/s00704-004-0044-9

[6] Rickenbach, T.M., Nieto Ferreira, R., Halverson, J., Herdies, D.L. and Silva Dias, M.A.F. (2002) Modulation of Convection in the Southwestern Amazon Basin by Extratropical Stationary Fronts. Journal of Geophysical Research, 107, 8040. http://dx.doi.org/10.1029/2000JD000263

[7] Pereira Filho, A.J., Silva Dias, M.A.F., Albrecht, R.I., Pereira, L.G.P., Tokay, A. and Rutledge, S. (2002) Multisensor Analysis of a Squall Line in the Amazon Region. Journal of Geophysical Research, 107, 8084, 21-1, 12, LBA Special Issue.

[8] Janowiak, J.E., Kousky, V.E. and Joyce, R.J. (2005) Diurnal Cycle of Precipitation Determined from the CMORPH High Spatial and Temporal Resolution Global Precipitation Analyses. Journal of Geophysical Research, 110, D23105. http://dx.doi.org/10.1029/2005JD006156

[9] Kousky, V.E., Janowiak, J.E. and Joyce, R.J. (2006) The Diurnal Cycle of Precipitation over South America Based on CMORPH. Proceedings of 8 ICSHMO, INPE, Foz do Iguaçu, 1113-1116.

[10] Huffman, G.J., Adler, R.F., Bolvin, D.T., Gu, G., Nelkin, E.J., Bowman, K.P., Hong, Y., Stocker, E.F. and Wolff, D.B. (2007) The TRMM Multi-Satellite Precipitation Analysis: Quasi-Global, Multi-Year, Combined-Sensor Precipitation Estimates at Fine Scale. Journal of Hydrometeorology, 8, 38-55. http://dx.doi.org/10.1175/JHM560.1

[11] Hsu, K.L., Gao, X., Sorooshian, S. and Gupta, H.V. (1997) Precipitation Estimation from Remotely Sensed Information Using Artificial Neural Networks. Journal of Applied Meteorology, 36, 1176-1190. 
http://dx.doi.org/10.1175/1520-0450(1997)036<1176:PEFRSI $>2.0 . C O ; 2$

[12] Carbone, R.E., Tuttle, J.D., Ahijevych, D.A. and Trier, S.B. (2002) Inferences of Predictability Associated with Warm Season Precipitation Episodes. Journal of the Atmospheric Sciences, 59, 2033-2056. http://dx.doi.org/10.1175/1520-0469(2002)059<2033:IOPAWW >2.0.CO;2

[13] Pereira Filho, A.J., Carbone, R.E. and Tuttle, J.D. (2014) Convective Rainfall Systems in the La Plata Basin. Atmospheric and Climate Sciences, 4, 757-778. http://dx.doi.org/10.4236/acs.2014.44068

[14] Laing, A.G., Carbone, R., Levizzani, V. and Tuttle, J. (2008) The Propagation and Diurnal Cycles of Deep Convection in Northern Tropical Africa. Quarterly Journal of the Royal Meteorological Society, 134, 93-109. http://dx.doi.org/10.1002/qi.194

[15] Peixoto, J.P. and Oort, A.H. (1992) Physics of Climate. American Institute of Physics, College Park, 520 p.

[16] Pereira Filho, A.J., Carbone, R.E., Janowiak, J.E., Arkin, P., Joyce, R., Hallak, R. and Ramos, C.G.M. (2010) Satellite Rainfall Estimates over South America-Possible Applicability to the Water Management of Large Watersheds. Journal of the American Water Resources Association, 46, 344-360. http://dx.doi.org/10.1111/j.1752-1688.2009.00406.x

[17] Liu, C. and Zipser, E.J. (2008) Diurnal Cycles of Precipitation, Clouds, and Lightning in the Tropics from 9 Years of Trmm Observations. Geophysical Research Letters, 35, L04819. http://dx.doi.org/10.1029/2007GL032437

[18] Wang, B. (2002) Kelvin Waves. Shankar, M., Ed., Elsevier Science Ltd., 7p. http://www.soest.hawaii.edu/

[19] Kiladis, G.N., Wheeler, M.C., Haertel, P.T., Straub, K.H. and Roundy, P.E. (2009) Convectively Coupled Equatorial Waves. Reviews of Geophysics, 47, RG2003/2009 1-42. http://dx.doi.org/10.1029/2008RG000266

[20] Keenan, T.D. and Carbone, R.E. (2008) Propagation and Diurnal Evolution of Warm Season Cloudiness in the Australian and Maritime Continental Region. Monthly Weather Review, 136, 973-994. http://dx.doi.org/10.1175/2007MWR2152.1

[21] Laing, A.G., Carbone, R. and Levizzani, V. (2011) Cycles and Propagation of Deep Convection over Equatorial Africa. Monthly Weather Review, 139, 2832-2853. http://dx.doi.org/10.1175/2011MWR3500.1

[22] Pereira Filho, A.J., Prado, L.F. and Santos, C.C. (2012) Precipitation Global, Regional and Local. In: Ciclo Ambiental da Água da Chuva à Gestão, Blucher Publisher, 93-116. (In Portuguese) 